\title{
Natural Quinone Dyes: A Review on Structure, Extraction Techniques, Analysis and Application Potential
}

\author{
Benson Dulo ${ }^{1,3} \cdot$ Kim Phan $^{1} \cdot$ John Githaiga ${ }^{2} \cdot$ Katleen Raes $^{3} \cdot$ Steven De Meester ${ }^{1}$
}

Received: 19 September 2020 / Accepted: 13 April 2021 / Published online: 10 May 2021

(c) The Author(s) 2021

\begin{abstract}
Synthetic dyes are by far the most widely applied colourants in industry. However, environmental and sustainability considerations have led to an increasing efforts to substitute them with safer and more sustainable equivalents. One promising class of alternatives is the natural quinones; these are class of cyclic organic compounds characterized by a saturated (C6) ring that contains two oxygen atoms that are bonded to carbonyls and have sufficient conjugation to show color. Therefore, this study looks at the potential of isolating and applying quinone dye molecules from a sustainable source as a possible replacement for synthetic dyes. It presents an in-depth description of the three main classes of quinoid compounds in terms of their structure, occurrence biogenesis and toxicology. Extraction and purification strategies, as well as analytical methods, are then discussed. Finally, current dyeing applications are summarised. The literature review shows that natural quinone dye compounds are ubiquitous, albeit in moderate quantities, but all have a possibility of enhanced production. They also display better dyeability, stability, brightness and fastness compared to other alternative natural dyes, such as anthocyanins and carotenoids. Furthermore, they are safer for the environment than are many synthetic counterparts. Their extraction, purification and analysis are simple and fast, making them potential substitutes for their synthetic equivalents.
\end{abstract}

\section{Graphic Abstract}

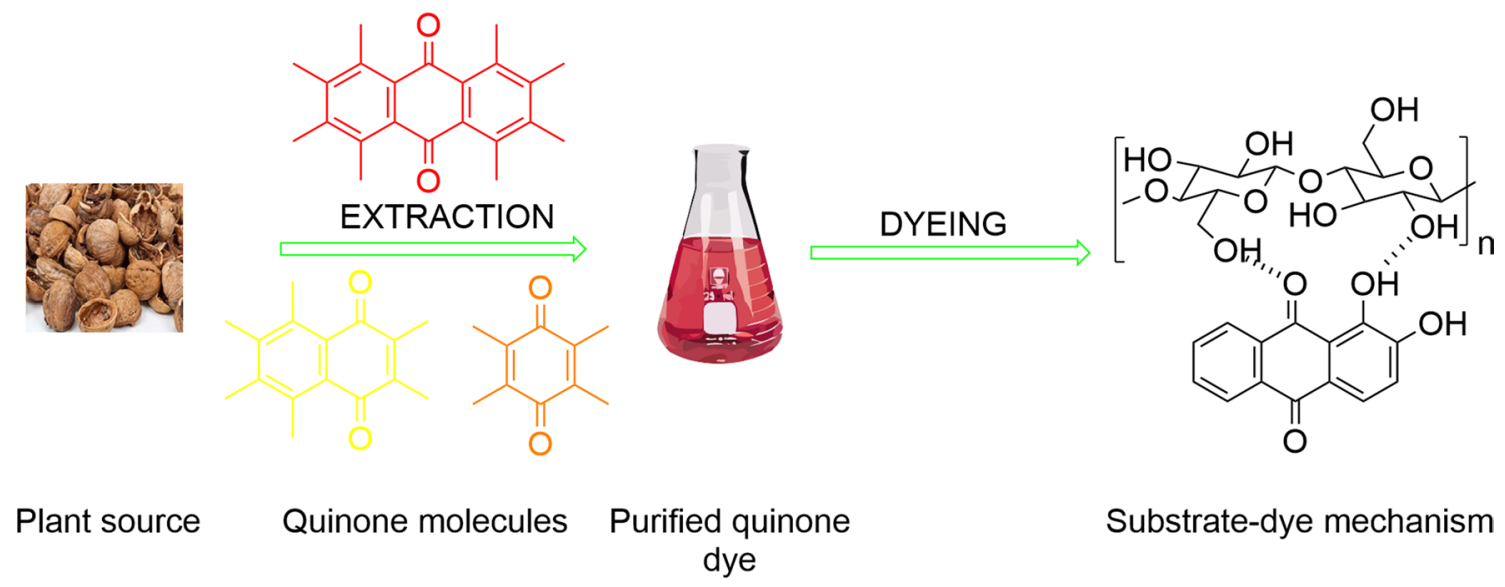

Keywords Natural dye $\cdot$ Extraction $\cdot$ Characterisation $\cdot$ Quinone $\cdot$ Sustainability $\cdot$ Biomass

Steven De Meester

Steven.DeMeester@UGent.be

Extended author information available on the last page of the article

\section{Statement of Novelty}

This paper evaluates natural quinone dyes as potential substitute for their synthetic equivalents. Sustainability and environmental safety will be achieved by the use of these dye extracts. Earlier studies concentrated on flavonoids and 
carotenoids whereas quinoids have not received similar attention, despite being at least as promising as the other two sources. The paper also presents an up-to-date overview of chemical analysis techniques and the use of natural quinone dyes.

\section{Introduction}

Dyes can generally be categorised as either synthetic or natural. While synthetic dyes are typically synthesised from petrochemical sources, natural colourants are abundantly available in nature and can be obtained from plants, microorganisms, animals or minerals. Of these sources, plants can potentially be a more sustainable source since plants biomass is more abundant in nature and contains dye molecules in higher quantities $[1,2]$. These dyes have been used for centuries for colouration of natural fibres, such as cotton, silk, and wool, as well as for other substrates like leather, skin, hair, shoe polish, paper, wood, cane, candles and food [3]. However, in the beginning of the twentieth century, the introduction of synthetic dyes resulted in a drastic decline in the use of natural dyes due to the low cost, availability, simplicity of application, colour range, shade reproducibility and superior colour fastness of the synthetics [4]. Nevertheless, in the past two decades, an upsurge has occurred in the use of natural dyes because of their potential eco-friendliness, biodegradability, renewability and lower toxicity to humans and the environment [5-7].

Natural dyes can be classified based on the dye source, application method and chemical structure. However, classification based on the chemical structure might be more appropriate since the structure uniquely identifies dyes belonging to a certain chemical group with specific properties $[5,8]$. On this basis, natural dyes are further grouped as indigoids, pyridine-based, carotenoids, quinoids, flavonoids, betalains, tannins and dihydropyrans [4, 5]. Of these groups, the quinoids, which include benzoquinones, naphthoquinones and anthraquinones are of particular interest since they resemble synthetic dyes [9] and may therefore be potential substitutes for the synthetic equivalents.

Synthetic dyes mainly consist of two major classes; azo dyes and anthraquinones dyes. The azo dyes, despite having many functional advantages, are now considered hazardous [10]. In fact, they are banned in many countries, such as the United States of America (U.S.A), India, and the European Union (E.U), among others [11, 12]. Many synthetic anthraquinones dyes, such as Disperse Blue 3, 2-aminoanthraquinone, and many others, have also been found to be highly toxic to humans and to the environment $[13,14]$.
The most abundant natural dyes are the carotenoids, flavonoids and quinones [15]. Of these, the carotenoids and flavonoids have been extensively studied and reviews are available [16-19]. By contrast, quinones have not been given similar attention, despite being at least as promising as the other two sources, since they can be considered the natural analogues of the more established synthetic quinone dyes. This review, therefore, aims to provide some insight into the potential of natural quinoid dyes. It gives a brief overview of the structure, occurrence, biogenesis, uses and toxicological analysis of these class of dyes. It also delves into quinone extraction, purification, identification, quantification and application in the context of dyeing. To ensure an exhaustive review, literature materials, such as text books, articles, abstracts and peer-reviewed publications listed in Web-of Science and Google scholar, were searched using the phrases "quinone dyes", "natural quinone", "natural dyes", "quinone compound", "natural anthraquinone", "natural naphthoquinone" and "natural benzoquinone" within the period 1998-2019.

\section{Structure, Occurrence, Use and Biogenesis of Natural Quinones}

Though quinone compounds are structurally the most varied dye molecules $[5,20]$, they all share some features, sources, usage and biosynthesis pathways as described below.

\section{Structure}

Quinones are coloured compounds with a basic benzoquinone chromophore (Fig. 1a) consisting of two carbonyl groups with two carbon-carbon double bonds. The quinone dyes are fused benzenoid quinoid ring systems with sufficient conjugation to achieve colour. The three main classes of quinones are benzoquinones (Fig. 1a), naphthoquinones (Fig. 1b) and anthraquinones (Fig. 1c), which contains 1, 2 and 3 ring structures respectively.

Benzoquinone (Fig. 1a) is the basic subunit of quinone compounds [21]. Chemically, 1,4-benzoquinone (also called para-benzoquinone) is a non-aromatic compound which is easily converted into hydroquinone on reduction [22]. Benzoquinone units serve as building blocks in quinone synthesis and provide important moieties for the biosynthesis of active biological compounds [21]. Compounds with para-benzoquinones attached to one more benzene ring at position 2,3-C (carbon), are called naphthoquinones. The naphthoquinone structure (Fig. 1b) has two carbonyl groups on one benzene ring, normally at the o- or p- orientation [23]. Naphthoquinones also have $\alpha$ - and $\beta$-unsaturated carbonyls. The extended electron delocalisation through the double bonds and the carbonyl groups gives rise to intense 
<smiles>[R]C1=C([R])C(=O)C([R])=C([R])C1=O</smiles>

a<smiles>[R]C1=C([R])C(=O)c2c([R3])c([R4])c([R5])c([R6])c2C1=O</smiles>

b<smiles>[R]c1c([R])c([R2])c2c(c1[R])C(=O)c1c([R6])c([R])c([R])c([R6])c1C2=O</smiles>

c

Fig. 1 Chemical structure of a benzoquinone, $\mathbf{b}$ naphthoquinone and $\mathbf{c}$ anthraquinone

colouration in the visible region [24]. The third class of quinones known as anthraquinones, are compounds containing the anthracene nucleus with two carbonyl groups, normally on the B-ring. They are derived from the basic structure 9,10-dioxoanthracene $\left(\mathrm{C}_{14} \mathrm{H}_{8} \mathrm{O}_{2}\right)$ (Fig. 1c), a tricyclic aromatic organic compound. The parent structure is also referred to as 9,10-anthracenedione, anthradione, 9,10-anthrachinon, anthracene-9-10 quinone, 9,10-dihidro-9, or 10-dioxoanthracene. Since quinone structures allow different substitution patterns, hundreds of derivatives exist in nature, especially for anthraquinones. Hydroxyanthraquinoids absorb visible light and are therefore coloured [25]. Generally, the colour of a quinone compound depends on the position, nature and number of hydroxyl and electrondonating/accepting constituents, also called auxochromes, on the different rings impacting on intra-molecular hydrogen bonding and steric effects [26]. Although the introduction of electro-donating substituents have little effect on quinones colouration, some substituents, such as amino or substituted amino groups, can have a significant impact on the dye's colour properties [26]. The structures and corresponding colours of commonly used coloured quinones are shown in Table 1.

\section{Occurrence}

Natural quinones constitute a large class of aromatic compounds that are prevalent in nature and can be found in several families of algae, fungi (including lichens), bacteria, flowering plants and arthropods [21,24]. They are also found in insects like cochineal (Dactylopius coccus) [27], kermes (Kermes vermilio) [28] and lac (Kerria lacca) [25]. However, they are principally isolated from flowering plants, in which their colours are normally masked by other pigments [23, 29].

Among the subclasses of quinones, anthraquinones form the largest group, with around 700 compounds studied. Of these nearly half are from plants alone [26], While the remainder originate from fungi, bacteria, lichens, and insects [30]. The anthraquinones mainly occur in the Rubiaceae,
Leguminosae, Polygonaceae, Bignoniaceae, Verbenaceae, Scrophulariaceae, and Liliaceae plant families. These compounds have been reported to exist in almost all parts of plants tissues and organs, such as leaves, stems, pods, seed coats, fruits, nut shells, flowers, tubers, leaf glands, root bark and heartwood [20, 31]. The most commonly occurring anthraquinone is emodin, due to its presence in moulds, lichens, higher fungi, flowering plants and insects as well [20]. Anthraquinones may also be hydroxylated and may occur in vivo in free (aglycone) forms, or in combined (glycoside) forms, or in reduced forms [32]. In plants, anthraquinones are mostly present as glycosides, which makes them water soluble and gives them a lower chemical reactivity towards other plant cell compounds [33]. Normally, the aglycone forms are converted into glycoside anthraquinones by $\beta$-glycosidase activity or through an oxidative process [26]. This process occurs when one or more sugar molecules such as rhamnose or glucose are bound to the hydroxyl group at position R-6 or R-8 (Fig. 1) [30]. Conversely, hydrolysis of these glycosides also occurs [32]. An example is the aglycosylated alizarin formed by removal of the disaccharide primevorose (6-O- $\beta$-D-xylopyranosyl- $\beta$-D-glucose) by hydrolysis of a glycosylated ruberythric acid [31]. Pure non-glycosylated anthraquinones have also been reported to occur in plants as well [34]. Anthrones, a reduced form of anthraquinones, have also been isolated from plants, as have diathrone dimers, such as rheum emodindiathrone, physiondiathrone and sennosoids which are formed by coupling of two single anthrones [35].

Anthraquinone sources under active study for dyeing purposes include Rubia cordifolia, and Rubia tinctorum which contains alizarin, purpurin, emodin and rhein as common pigments [36, 37]; Rheum emodi which contains contains emodin and physcion colourants [38]; Cassia nodosa, which contains rhein [39]; and Morinda angustifolia, which contains rhein and emodin dye compounds [40]. Anthraquinone pigments have been isolated in concentrations in excess of $30 \mathrm{mg} /(\mathrm{g} \mathrm{dw})$ (dw: dry weight) from Morinda citrifolia, $R$. emodi, Rheum undulatum, Rubia cardigolia and Tectona grandis [38, 41, 42]. 
Table 1 Common quinone dye structures [20, 25]

\begin{tabular}{|c|c|c|c|c|c|c|c|c|c|c|}
\hline Dye compound & Formula & Colour & $\mathrm{R} 1$ & $\mathrm{R} 2$ & R3 & R4 & R5 & R6 & R7 & R8 \\
\hline \multicolumn{11}{|l|}{ Anthraquinones } \\
\hline Alizarin & $\mathrm{C}_{14} \mathrm{H}_{8} \mathrm{O}_{4}$ & Red & $\mathrm{OH}$ & $\mathrm{OH}$ & $\mathrm{H}$ & $\mathrm{H}$ & $\mathrm{H}$ & $\mathrm{H}$ & $\mathrm{H}$ & $\mathrm{H}$ \\
\hline Emodin & $\mathrm{C}_{15} \mathrm{H}_{10} \mathrm{O}_{5}$ & Yellow & $\mathrm{OH}$ & $\mathrm{H}$ & $\mathrm{CH}_{2} \mathrm{OH}$ & $\mathrm{H}$ & $\mathrm{H}$ & $\mathrm{H}$ & $\mathrm{H}$ & $\mathrm{OH}$ \\
\hline Carminic acid & $\mathrm{C}_{22} \mathrm{H}_{20} \mathrm{O}_{13}$ & Red & $\mathrm{OH}$ & Glucose & $\mathrm{OH}$ & $\mathrm{OH}$ & $\mathrm{H}$ & $\mathrm{OH}$ & $\mathrm{COOH}$ & $\mathrm{CH}_{3}$ \\
\hline Kermesic acid & $\mathrm{C}_{16} \mathrm{H}_{10} \mathrm{O}_{8}$ & Red & $\mathrm{OH}$ & $\mathrm{H}$ & $\mathrm{OH}$ & $\mathrm{OH}$ & $\mathrm{H}$ & $\mathrm{OH}$ & $\mathrm{COOH}$ & $\mathrm{CH}_{3}$ \\
\hline Lucidin- $O$-primeveroside & $\mathrm{C}_{15} \mathrm{H}_{10} \mathrm{O}_{5}$ & Yellow & $\mathrm{OH}$ & $\mathrm{CH}_{2} \mathrm{OH}$ & $\mathrm{OH}$ & $\mathrm{H}$ & $\mathrm{H}$ & $\mathrm{H}$ & $\mathrm{H}$ & $\mathrm{H}$ \\
\hline Morindone & $\mathrm{C}_{15} \mathrm{H}_{10} \mathrm{O}_{5}$ & Red, brown, orange & $\mathrm{OH}$ & $\mathrm{OH}$ & $\mathrm{H}$ & $\mathrm{H}$ & $\mathrm{OH}$ & $\mathrm{CH}_{3}$ & $\mathrm{H}$ & $\mathrm{H}$ \\
\hline Munjistin & $\mathrm{C}_{15} \mathrm{H}_{8} \mathrm{O}_{6}$ & Red & $\mathrm{OH}$ & $\mathrm{COOH}$ & $\mathrm{OH}$ & $\mathrm{H}$ & $\mathrm{H}$ & $\mathrm{H}$ & $\mathrm{H}$ & $\mathrm{H}$ \\
\hline Physcion & $\mathrm{C}_{16} \mathrm{H}_{12} \mathrm{O}_{5}$ & Yellow & $\mathrm{OH}$ & $\mathrm{H}$ & $\mathrm{CH}_{3}$ & $\mathrm{H}$ & $\mathrm{H}$ & $\mathrm{OCH}_{3}$ & $\mathrm{H}$ & $\mathrm{OH}$ \\
\hline Pseudopurpurin & $\mathrm{C}_{15} \mathrm{H}_{8} \mathrm{O}_{7}$ & Red, yellow & $\mathrm{OH}$ & $\mathrm{COOH}$ & $\mathrm{OH}$ & $\mathrm{OH}$ & $\mathrm{H}$ & $\mathrm{H}$ & $\mathrm{H}$ & $\mathrm{H}$ \\
\hline Purpurin & $\mathrm{C}_{14} \mathrm{H}_{8} \mathrm{O}_{5}$ & Red & $\mathrm{OH}$ & $\mathrm{OH}$ & $\mathrm{H}$ & $\mathrm{OH}$ & $\mathrm{H}$ & $\mathrm{H}$ & $\mathrm{H}$ & $\mathrm{H}$ \\
\hline Quinizarin & $\mathrm{C}_{15} \mathrm{H}_{10} \mathrm{O}_{3}$ & Green & $\mathrm{OH}$ & $\mathrm{CH}_{2} \mathrm{OH}$ & O-pr & $\mathrm{H}$ & $\mathrm{H}$ & $\mathrm{H}$ & $\mathrm{H}$ & $\mathrm{H}$ \\
\hline Rhein & $\mathrm{C}_{15} \mathrm{H}_{8} \mathrm{O}_{6}$ & Yellow & $\mathrm{OH}$ & $\mathrm{H}$ & $\mathrm{COOH}$ & $\mathrm{H}$ & $\mathrm{H}$ & $\mathrm{H}$ & $\mathrm{H}$ & $\mathrm{OH}$ \\
\hline Ruberythric acid & $\mathrm{C}_{25} \mathrm{H}_{26} \mathrm{O}_{13}$ & Yellow & $\mathrm{OH}$ & $-\mathrm{pr}$ & $\mathrm{H}$ & $\mathrm{H}$ & $\mathrm{H}$ & $\mathrm{H}$ & $\mathrm{H}$ & $\mathrm{H}$ \\
\hline Rubiadin & $\mathrm{C}_{15} \mathrm{H}_{10} \mathrm{O}_{4}$ & Yellow & $\mathrm{OH}$ & $\mathrm{CH}_{3}$ & $\mathrm{OH}$ & $\mathrm{H}$ & $\mathrm{H}$ & $\mathrm{H}$ & $\mathrm{H}$ & $\mathrm{H}$ \\
\hline Xanthopurpurin & $\mathrm{C}_{14} \mathrm{H}_{8} \mathrm{O}_{4}$ & Red & $\mathrm{OH}$ & $\mathrm{H}$ & $\mathrm{OH}$ & $\mathrm{H}$ & $\mathrm{H}$ & $\mathrm{H}$ & $\mathrm{H}$ & $\mathrm{H}$ \\
\hline \multicolumn{11}{|l|}{ Naphthoquinones } \\
\hline Lawsone & $\mathrm{C}_{10} \mathrm{H}_{6} \mathrm{O}_{3}$ & Orange, brown & $\mathrm{OH}$ & $\mathrm{H}$ & $\mathrm{H}$ & $\mathrm{H}$ & $\mathrm{H}$ & $\mathrm{H}$ & & \\
\hline Alkannin & $\mathrm{C}_{16} \mathrm{H}_{16} \mathrm{O}_{5}$ & Red, orange, brown & $\mathrm{H}$ & $\mathrm{H}$ & $\mathrm{HO}$ & $\mathrm{H}$ & $\mathrm{H}$ & $\mathrm{H}$ & & \\
\hline Shikonin & $\mathrm{C}_{16} \mathrm{H}_{16} \mathrm{O}_{5}$ & Red, yellow, brown & $\mathrm{H}$ & $\mathrm{H}$ & $\mathrm{HO}$ & $\mathrm{H}$ & $\mathrm{H}$ & $\mathrm{H}$ & & \\
\hline Juglone & $\mathrm{C}_{10} \mathrm{H}_{6} \mathrm{O}_{3}$ & Brown & $\mathrm{H}$ & $\mathrm{H}$ & $\mathrm{HO}$ & $\mathrm{H}$ & $\mathrm{H}$ & $\mathrm{H}$ & & \\
\hline Lapachol & $\mathrm{C}_{16} \mathrm{H}_{16} \mathrm{O}_{3}$ & Yellow & $\mathrm{OH}$ & $\mathrm{H}$ & $\mathrm{H}$ & $\mathrm{H}$ & $\mathrm{H}$ & $\mathrm{H}$ & & \\
\hline Plumbargin & $\mathrm{C}_{11} \mathrm{H}_{8} \mathrm{O}_{3}$ & Yellow & $\mathrm{CH}_{3}$ & $\mathrm{H}$ & $\mathrm{OH}$ & $\mathrm{H}$ & $\mathrm{H}$ & $\mathrm{H}$ & & \\
\hline 6-Methyl-naphthoquinone & $\mathrm{C}_{11} \mathrm{H}_{8} \mathrm{O}_{2}$ & Yellow & $\mathrm{H}$ & $\mathrm{H}$ & $\mathrm{H}$ & $\mathrm{CH}_{3}$ & $\mathrm{H}$ & $\mathrm{H}$ & & \\
\hline \multicolumn{11}{|l|}{ Benzoquinone } \\
\hline Carthamine & $\mathrm{C}_{25} \mathrm{H}_{8} \mathrm{O}_{3}$ & Yellow, green, red & $\mathrm{O}$ & $\mathrm{O}$ & $\mathrm{H}$ & $\mathrm{HO}$ & & & & \\
\hline
\end{tabular}

- $p r$ primeveroside

Numbers in Table 1 correspond with the numbers in Fig. 1

Naphthoquinones, with more than 120 sources studied, are the second most common group of quinones found in nature. They exist as several isomers, with the 1,4-naphthoquinones being the most common and the most stable [43]. This class of compounds is fairly broadly distributed among plants and microorganisms, while some are occasionally found in animals and specific fungi, and as metabolic product of some bacteria [23]. In plants, naphthoquinones frequently occur individually but sometimes co-exist with anthraquinones in the same species, particularly in the Bignoniaceae and Verbenaceae families [20]. They normally occur in the free form but sometimes exist in vivo as glycosides. In animals, naphthoquinones have been isolated from echinoderms, significantly from sea stars, starfish, sea urchins and from aphid species [20]. The commonly occurring 1,4-naphthoquinone compounds in plants are lawsone or henna in Lythraceae [24]; juglone in Lawsonia inermis [44]; and plumbagin in the Juglandaceae [45]; alkannin and shikonin in Plumbaginaceae [46] and lapachol pigment in the Borginaceae [47]. Naphthoquinone pigment concentration values as high as $50 \mathrm{mg} /(\mathrm{g} \mathrm{dw})$ have been obtained from Juglans regia, and Tecomella undulata [42, 48].

Of the three classes of quinones, benzoquinone is the least prevalent. However, it has been reported to occur in flowering plants, in fungi, in lichens, and in insects like beetles, millipedes and other arthropods capable of synthesising benzoquinone and its derivatives [20]. These compounds have been isolated from all parts of higher plants and usually occur as a single entity, with a few alkylated quinones and biquinones frequently occurring together [20]. The benzoquinone from plant biomass that is most commonly studied as a dye compound is carthamin, found in safflower (Carthamus tinctorius) [49]. A high concentration of about $30 \mathrm{mg} /(\mathrm{g} \mathrm{dw})$ have been isolated from safflower [50]. Common sources and occurrence of natural quinones are summarised in Table 2, together with the tissue from which the compounds are extracted and the colors and concentrations obtained.

Apart from plant sources, microbial organisms, such as fungi (including lichens), bacteria and algae, are other 
Table 2 Survey of common sources of quinones components

\begin{tabular}{|c|c|c|c|c|c|c|}
\hline Source & Common name & Part used & Compound & Colour & $\begin{array}{l}\text { Concentration } \mathrm{mg} / \\
(\mathrm{g} \mathrm{dw})\end{array}$ & $\begin{array}{l}\text { Refer- } \\
\text { ences }\end{array}$ \\
\hline \multicolumn{7}{|l|}{ Anthraquinones } \\
\hline $\begin{array}{l}\text { Cassia occiden- } \\
\text { talis }\end{array}$ & Kasunda-hindi & All parts & $\begin{array}{l}\text { Emodin, rhein, } \\
\text { physcion }\end{array}$ & Yellow & 11.1 & {$[60]$} \\
\hline Cassia fistula & Indian laburnum & Whole plant & $\begin{array}{l}\text { Rhein, sennoside, } \\
\text { physcion, aloe- } \\
\text { emodin }\end{array}$ & Yellow & $\begin{array}{l}\text { Total glycoside in } \\
\text { leaves } 3.6 \pm 0.16\end{array}$ & {$[61]$} \\
\hline $\begin{array}{l}\text { Dermocybe san- } \\
\text { guinea }\end{array}$ & Blood red redcap & Stem, cups, Fruit & $\begin{array}{l}\text { Emodin, Physcion, } \\
\text { Enductrocin, } \\
\text { Dermolutein }\end{array}$ & $\begin{array}{l}\text { Yellow, orange, red } \\
\text { and pink }\end{array}$ & 0.0057 & [9] \\
\hline Morinda citrifolia & Indian Mulberry & Roots & Morindone & Red & $0.6-1.2$ & {$[62,63]$} \\
\hline $\begin{array}{l}\text { Morinda angus- } \\
\text { tifolia }\end{array}$ & $\begin{array}{l}\text { Noni, Indian Mul- } \\
\text { berry }\end{array}$ & Roots & Morindone & Brown/orange & 40.0 & {$[42]$} \\
\hline $\begin{array}{l}\text { Oldenlandia } \\
\text { umbellata }\end{array}$ & $\begin{array}{l}\text { Chay root, Indian } \\
\text { madder }\end{array}$ & Roots & $\begin{array}{l}\text { Hydroxy- and } \\
\text { methoxy- anth- } \\
\text { raquinone }\end{array}$ & Brown & 0.4 & {$[64]$} \\
\hline Rhamnus frangula & Buckthorn & Bark & frangulin (rhamnox) & Green, yellow & 19.0 & {$[65]$} \\
\hline Rheum emodi & $\begin{array}{l}\text { Himalayan rhubarb, } \\
\text { Indian rhubarb }\end{array}$ & Rhizome & $\begin{array}{l}\text { Rhein, Emodin, } \\
\text { Physcion, Chrys- } \\
\text { ophanol, Aloe- } \\
\text { emodin,rutin }\end{array}$ & Yellow & Rhizome: 46.1 & {$[38]$} \\
\hline Rheum undulatum & Rhabarbarum & $\begin{array}{l}\text { Leaves, Rhyzome, } \\
\text { Roots }\end{array}$ & $\begin{array}{l}\text { Emodin, chrysopha- } \\
\text { nol and physcion }\end{array}$ & Yellow & Roots: 34.0 & {$[41]$} \\
\hline Rubia cordifolia & Indian madder & Root, stem & $\begin{array}{l}\text { Purpurin, alizarin, } \\
\text { munjistin, }\end{array}$ & Red, red & Stem: 45.0 & [42] \\
\hline Rubia tinctorum & Dyer's madder & Root & Alizarin & Red & 7.7 & {$[66]$} \\
\hline $\begin{array}{l}\text { Fusarium oxyspo- } \\
\text { rum }\end{array}$ & Fusarium wilt & Tissue culture & Anthraquinone & Pink/violet & N.D & {$[54]$} \\
\hline $\begin{array}{l}\text { Penicillium oxali- } \\
\quad \text { cum }\end{array}$ & Sorghum spp. & Tissue culture & Anthraquinone & Red & $1.5-2 \mathrm{~g} / \mathrm{L}$ & {$[67]$} \\
\hline \multicolumn{7}{|l|}{ Naphthoquinones } \\
\hline $\begin{array}{l}\text { Fusarium verticil- } \\
\text { lioides }\end{array}$ & Basal rot & Tissue culture & Naphthoquinone & Yellow & $2.5 \mathrm{~g} / \mathrm{L}$ & {$[68]$} \\
\hline Alkanna tinctoria & $\begin{array}{l}\text { Dyer's alkanet, } \\
\text { alkanet }\end{array}$ & Whole plant, Root & Alkanin, Shikonin & Red, yellow, brown & $\begin{array}{l}\text { Roots } \\
\text { Alkanin:14.1 } \\
\text { Shikonin: } 5.6\end{array}$ & [69] \\
\hline Juglans regia & Walnut & $\begin{array}{l}\text { Bark, root, shell, } \\
\text { leaf }\end{array}$ & Juglone & Brown & Shell: 50.0 & [48] \\
\hline Lawsonia inermis & Henna, Hina & Leaves & Lawsone & Orange, brown & $18.5-18.7$ & [70] \\
\hline $\begin{array}{l}\text { Impatiens glandu- } \\
\quad \text { lifera }\end{array}$ & $\begin{array}{l}\text { Ornamental jewel } \\
\text { weed }\end{array}$ & $\begin{array}{l}\text { Leaves, stem, flow- } \\
\text { ers }\end{array}$ & Lawsone & Orange, brown & $8.0-11.0$ & {$[71]$} \\
\hline $\begin{array}{l}\text { Onosma nigri- } \\
\text { caule }\end{array}$ & Havacica & Roots & Shikonin/Alkanin & Red & 2.2 & {$[72]$} \\
\hline Tectona grandis & Teak & Branches, leaves & Lapachol & Yellow & Leaves: 50.0 & [42] \\
\hline \multicolumn{7}{|l|}{ Benzoquinone } \\
\hline $\begin{array}{l}\text { Carthamus tinc- } \\
\text { torius }\end{array}$ & Safflower & Flower & $\begin{array}{l}\text { Carthamin yellow } \\
\text { and Carthamin red }\end{array}$ & Yellow, green, red & $\begin{array}{l}\text { Red: } 3.2-8.8 \\
\text { Yellow: } 30.0\end{array}$ & {$[50]$} \\
\hline
\end{tabular}

major sources of natural quinone dyes. The advantage of microbial colourants is that the these sources can be cultured in different environments and due to the possibility of genetic modification, a high-quality coluorant can be achieved [51]. In fungi, anthraquinones have been isolated from Aspergillus sp., Eurotium sp., Emericella sp., Fusarium sp., Penicillium sp., Mycosphaerella sp., Microsporum sp., and as naphthoquinone from Trypethelium eluteriae [52], and benzoquinone from Beauveria bassiana [53], among others [54]. The fungi produce pigments, including chrysophanol and 1-acetyl-3, 8-dihydro6-methoxyanthraquinone, which are capable of producing 
a wide array of colourant shades, including red, bronze, maroon and red-brown [55]. In bacteria, quinones such as 2-hydroxy-9,10-anthraquinone and naphthoquinone have been isolated from Streptomyces olivochromogenes [56] and Streptomyces sp. [57], respectively. In.algae, 2,6-dichloro-1,4-benzoquinone has been found in green algae [58], 1,4-napthoquinone in brown algae [59] and 1-methyl emodin anthraquinone in red algae among others.

Table 2 shows that quinones can be found in all plant parts at varying concentrations: leaves $(50 \mu \mathrm{g} / \mathrm{g} \mathrm{dw})$, stems $(45 \mu \mathrm{g} / \mathrm{g} \mathrm{dw})$, pods $(0.31 \mu \mathrm{g} / \mathrm{g} \mathrm{dw})$, seed coats $(8.34 \mu \mathrm{g} / \mathrm{g}$ $\mathrm{dw})$, fruits and nut shells $(50 \mu \mathrm{g} / \mathrm{g} \mathrm{dw})$, flowers $(8.8 \mu \mathrm{g} / \mathrm{g}$ $\mathrm{dw})$, tubers/rhizomes (46.08 $\mu \mathrm{g} / \mathrm{g} \mathrm{dw})$, root back $(190 \mu \mathrm{g} / \mathrm{g}$ $\mathrm{dw})$, wood heart (36 $\mu \mathrm{g} / \mathrm{g} \mathrm{dw})$, and whole plants $(11.07 \mu \mathrm{g} / \mathrm{g}$ $\mathrm{dw})$.

\section{Biogenesis}

Two different pathways have been proposed as biosynthesis routes for natural quinones in plants and other organisms (Fig. 2) [25, 73]. The first pathway is the polyketide or acetate-malonate pathway (Fig. 2a). The route involves systematic ring closure occurring on both aromatic rings and a substitution of at least two hydroxyl groups in the R1 and R8 positions (Fig. 1). This causes suitable folding and condensation of an octaketide chain derived from acetate and monolite. For example, in emodin pigment synthesis, the main precursor is the octaketide emodin anthrone, which results from a polyketide condensation reaction between acetyl-coenzyme A (-CoA) and malonyl-CoA fixed by a polyketide synthase (PKS) [74]. The anthrone is then oxidised into an emodin compound. The second proposed pathway is called the shikimate or chorismate/O-succinylbenzoic acid pathway (Fig. 2b). Here, pigments eventually only have one of the rings unsubstituted and at least one hydroxyl group on the R1 (Fig. 1) position, as in alizarine, pseudopurpurin, purpurin and lucidin [74].

To increase the production yield of natural quinones for industrial applications, biotechnological methods have been attempted based on the simulation of quinone's biosynthesis pathways. In microbial organisms, for example, three production mechanisms are proposed: genetic manipulation by sequencing the microbial genome, molecular screening to improve gene expression and optimisation of secretion of quinones compounds and the use of strategic procedures under optimal conditions to increase the colourant excretion [75]. Other methods include tissue culture. For example, the enhancement of quinone yield from Frangula alnus has been investigated and has led to a total anthraquinone content of $1731 \mathrm{mg} / 100 \mathrm{~g}$ in the cultured plant leaf [76]. Precursor addition has also been investigated and was found to double anthraquinone yield in Rubia akane cell cultures [77]. Working with cell cultures has also been proposed to generate quinone extract of high purity [78]

\section{Biological and Industrial Applications}

Quinones are key secondary metabolites with vital biological functions, such as oxidative phosphorylation and electron transfer in photosynthesis and respiration processes within the plant system [30]. These compounds often act as an intermediates between a plant and its environment and are responsible for fragrance, flavour, defence, signalling, color and energy transduction [26, 79]. For humans, natural quinone components have found applications in pharmacology for inducing cytoprotection through antifungal [80],

a

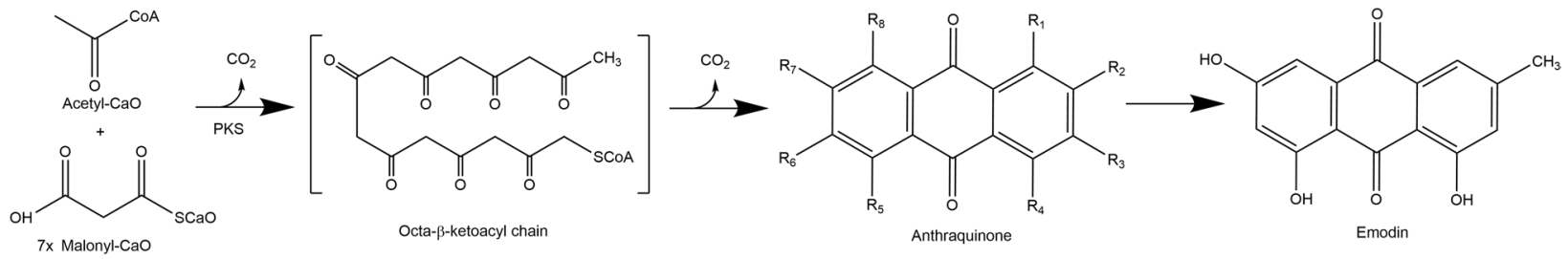

b

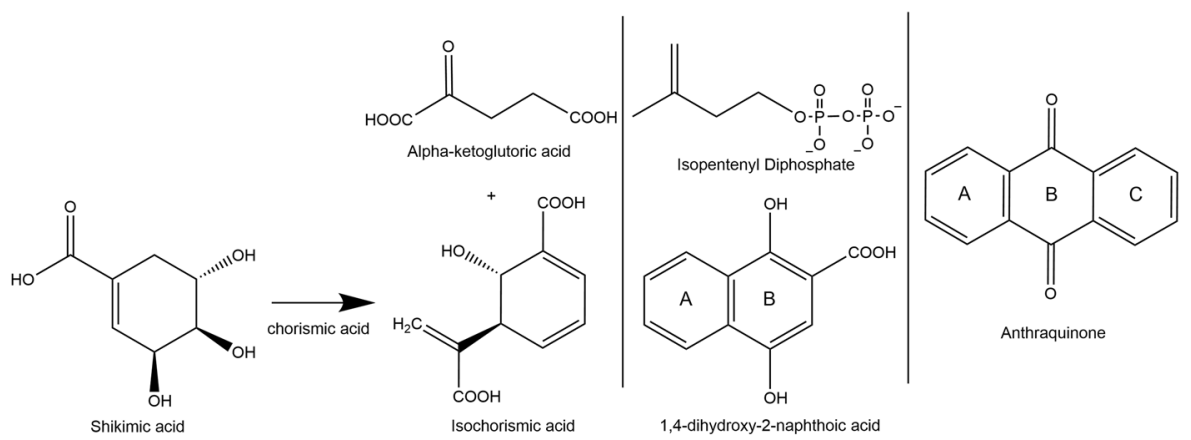

Fig. 2 Natural quinone biosynthesis pathways a acetic-malonate pathway [74] and b shikimate pathway [25] 
antibacterial [81], antioxidant, anti-cancer, anti-inflammatory, laxative [26], anti-allergens and anti-moth properties [82]. They are also used as histological stains [8] and insect repellant [83] and in engineering technology for metallic corrosion protection [84], as $\mathrm{pH}$ indicators [64], in energy harvesting processes [85] and industrial colouration [26].

Quinones also have potential binding affinity to different cell receptor moieties. They display different affinity, selectivity, functionality and exchange dynamics towards different cellular binding sites. Hydrogen bonding, hydrophobic, electrostatic and van der Waals are among the dominant interactions between quinones and other receptors [86, 87]. Therefore, the many substitution sites in the long conjugated chain of quinone dye molecules lead to attractive affinity between a ligand molecule and a substrate. Quantitative structure-activity relationships studies have demonstrated at least an appreciable similarity between dye-substrate interactions and receptor-ligand interactions, indicating the possibility of modulating fiber-substrate affinity to benefit dyeing application [87].

\section{Toxicity of Natural Quinones}

The natural origin of molecules, in this case quinones, does not guarantee that they are harmless. Indeed, some natural quinones, such as anthraquinones from Rumex patientia that are used in the pharmaceutical and food industries, can cause pathological effects in vivo if used at high doses ( $\geq 4000 \mathrm{mg} / \mathrm{kg}$ ), whereas lower doses produce slight or nonsignificant effects [88]. One report on the toxicity of various natural anthraquinones indicated a potential health and genotoxic effect on animals and humans if these quinones, and especially their aglycones, are directly ingested into the body in large quantity $(\geq 1000 \mathrm{mg} / \mathrm{kg}$ ) for a longer period (at least 2 weeks), despite their low bioavailability $(<0.1)$ [89] Nevertheless, when compared with synthetic anthraquinone or azo dyes, the natural substances are less harmful. Indeed, the synthetic counterparts are non-biodegradable and recalcitrant in nature, so they cannot be easily removed by wastewater treatments. By contrast, the effluents from natural dyes like quinones are easily degradable and do not require the extensive and costly treatment plants needed for the synthetic counterparts [90].

One study that examined the use of natural naphthoquinones, such as juglone and plumbagin to control nuisance towards aquatic species showed that these two biocides had relatively short half-lives in saline water ( $5 \mathrm{~h}$ to $30 \mathrm{~h}$ ), with juglone being more stable in fresh water [91]. The synthetic Reactive Blue 19 dye, in comparison, would take 46 years at $\mathrm{pH} 7$ and $25^{\circ} \mathrm{C}$ [92]. The study also determined that juglone, although stable in water, had little capacity for adsorption to suspended particulates or for bioaccumulation due to its low octanol-water partition coefficient $(\approx 2)$. The study concluded that, due to the rapid degradation, and especially in the marine environment, and the low adsorbency and bioaccumulation, the risk of residual toxicity is low for the release of juglone-treated water [91]. Generally, a reduction occurs in the pollution load when natural quinone dyes are used instead of their synthetic counterparts. A fact sheet on toxicological studies conducted on natural quinones, such as anthraquinones, reports that they are safe when used for nonfood purposes [93]. An example is lawsone, a naphthoquinone dye, used in cosmetics; this dye has not been included among the 49 toxic cosmetic dyes banned by the EU as it presented low to negligible genotoxic risks to consumers $[94,95]$. Contrarily, synthetic dyes such as Disperse Blue 3 displays acute toxicity [13], Vat Acid Blue 43 is potentially mutagenic, 2-aminoanthraquinone is identified as carcinogenic and Disperse Red 15 can cause allergic reactions [14]. However, these toxic effects, for either synthetic or natural quinone dyes, depend on the degree of exposure to the dye compounds.

The use of natural quinones as colorants has the advantage that these compounds also impart antibacterial [41, 96, 97], antifungal [98] anti-insect [83], and ultraviolet (UV) protection properties to textiles $[99,100]$. Based on these findings, natural quinones are not without risk, and should not immediately be considered as 'green' and harmless, however, generally speaking, they might pose relatively lower risks compared to the synthetically produced quinone variants currently in use.

\section{Purification of Quinone Dyes}

The different subclasses and varying substitution patterns of quinones means that their identification and purification are not straightforward, but rather complex. However, recent advances in analytical techniques now allow a better understanding of their nature and extraction potential. Therefore, this section of the paper discusses the extraction and purification of, quinone molecules.

\section{Extraction Parameters}

As with other plants chemicals, the extraction of quinone is influenced by factors like the amount of solvent (s) used, extraction time and temperature, equipment design, selectivity of the target component, amount of sample used, extraction efficiency and nature and condition of the matrix. Of these factors, the nature of the solvents is the most important as this determines the solubility of the target compound and extraction efficiency. A good quinone solvent should have a high extraction capacity, low boiling temperature and low latent heat of evaporation to allow separation at low temperature, as this reduces the energy demand to a minimum, and 
suppresses side reactions with colours and pigments to avoid loss of colour quality [36]. To a great extent, the solubility, and hence the extraction of substances, is dependent on the solute-solvent interaction [101]. The Hansen solubility theory illustrated in Eq. 1, can be used to predict this solubility [102]. The theory is based on three major intramolecular forces, namely dispersion $\left(\delta_{d}\right)$, polarity $\left(\delta_{p}\right)$ and hydrogen bonding $\left(\delta_{h}\right)$ [103]. The ability and efficiency of a solvent to dissolve a solute can therefore be estimated by determining the distance between the solute and the solvent or the relative energies according to Eq. 1:

$D_{S-P}=\sqrt{4 *\left(\delta_{d, P}-\delta_{d, S}\right)^{2}+\left(\delta_{p, P}-\delta_{p, S}\right)^{2}+\left(\delta_{h, P}-\delta_{h, S}\right)^{2}}$

where $\delta_{i, P}$ and $\delta_{i, S}\left(\mathrm{MPa}^{1 / 2}\right)$ are the $i$ th component of quinone polymer compound and solvent, respectively [103].

Two chemicals are mutually soluble if their solubility parameters (thus $D_{S-P}$ ) are approximately equal. By plotting the Hansen solubility points on a 3D graph, the solubility of a compound can be predicted. Based on this solubility theory, the solvents for extracting quinones are predictable as shown in Fig. 3.

As shown in Fig. 3, methanol-water and ethanol-water mixtures are the recommended solvents for the extraction of anthraquinones. Methanol or ethanol are also good solvents for anthraquinones and naphthoquinones. Benzoquinone shows a high solubility in solvents with relatively lower polarity, such as ethyl acetate, tetrahydrofuran, dichloromethane and butanol. Glycosides seemingly dissolve best in water and water-alcohol mixtures, whereas aglycones appear to be more readily soluble in alcohol-based solvents. These predictions are supported by the findings listed in Table 3, which shows that alcohol-water based extracts, having lower relative energy differences $(\leq 1)$, generates higher anthraquinone yields (about twofold) compared to solvents such as water, ethanol or benzene that all have higher relative energy differences $(>1)[104,105]$. Higher quantities (up to 7\%) of anthraquinones were also obtained when methanol or ethanol ware used as solvents rather than apolar solvents, again reflecting the lower relative energy towards anthraquinones [106]. Indeed, when comparing the quantity of the anthraquinone alizarin produced in different solvents, the yield decreased in the following order, in accordance with the increase in relative energy difference: methanol $(0.15 \%)$, ethanol $(0.03 \%)$, ethyl ether $(0.018 \%)$, and acetone $(0.018 \%)$ [36]. The same can also be seen for naphthoquinones extracted under similar conditions, where different solvents resulted in different yields: methanol $(0.06 \%)$, chloroform $(0.0146 \%)$ and ethyl acetate $(0.009 \%)$ [107]. Another study showed that methanol gave a higher weight concentration of juglone $(0.99 \%)$ than was obtained with acetone $(0.88 \%)$ when extracted under what were otherwise the same conditions [108]. Conversely, benzoquinone was obtained in a high quantity $(1.45 \%)$ when chloroform was used as the extraction solvent [109] while alcohol-water mixtures gave higher values for glycosides (2.63-4.6\%) [104].

Quinone isolation depends largely on whether aglycones or glycosides are targeted [36, 66]. However, sequential extraction with solvents of increasing dielectric constant or polarity is normally recommended when total quinones are of interest [33]. Additionally, since quinones vary in polarity and solubility, no particular solvent can be recommended for their complete extraction [20]. Another point of attention is that quinone extraction can be done at different temperatures. However, extracting anthraquinones at temperatures above $65^{\circ} \mathrm{C}$ or over $78^{\circ} \mathrm{C}$ in methanol or ethanol based solvents, respectively, for prolonged periods $(>9 \mathrm{~h}$ ) can result in the formation of artefacts, such as 2-ethoxyethyl or 2-ethoxymethyl groups $[33,110]$. Therefore, high-temperature extraction for longer periods should be avoided when using these two solvents [20]. These artefacts are undesirable since they modify the colour of the compounds [111].

Generally, quinone glycosides hydrolyses to their corresponding aglycones when exposed to high temperatures [112], in acidic conditions, for example, in (2-5\%) sulphuric and hydrochloride acid solution at temperatures between 80 and $100{ }^{\circ} \mathrm{C}$ [113], they can also be partially hydrolysed by aquous sodium hydroxide [114], and completely hydralysed by enzymatic (such as $\beta$-glucosidase) treatment at a temperature of $50^{\circ} \mathrm{C}$ and $\mathrm{pH} 5$ [115]. Nevertheless, a comparison of solvents such as ethanol and water for extraction of alizarin from madder root [112], revealed that ethanol was preferable since it gave a higher yield of glycosides. This does not correspond with the Hansen solubility prediction, as water was expected to result in higher extraction yields of alizarin glycosides. However, the alizarin glycoside-to-aglycone ratio was found to be $237: 1 \mathrm{mg} / \mathrm{cm}^{3}$ in ethanol and $22: 1 \mathrm{mg} / \mathrm{cm}^{3}$ in water. The lower amount of glycoside in water possibly reflected hydrolysis of the glycosides due to the use of high extraction temperatures [112]. To mitigate this, the current literature suggests that quinones be extracted at room temperature up to about $70-90{ }^{\circ} \mathrm{C}$ and preferably during shorter time frames or with higher temperature (about $98{ }^{\circ} \mathrm{C}$ ) for fewer hours $(<9 \mathrm{~h})$ (Table 3$)$.

Quinones also dissolve well in alkaline solutions [20, 50]. Teruyuki et al. [115] reported a selective and simultaneous extraction of both aglycones and glycosides using two phase extraction with chloroform and a potassium hydroxide solution. When potassium hydroxide solution was used as a solvent, both ruberythric acid and lucidin primeveroside were extracted, whereas only chloroform was used, anthraquinones primeverosides were not extracted and only small amounts of alizarin and lucidin were obtained. When both aqueous potassium hydroxide salt-chloroform solutions were used, alizarin and lucidin (in the chloroform phase) were 


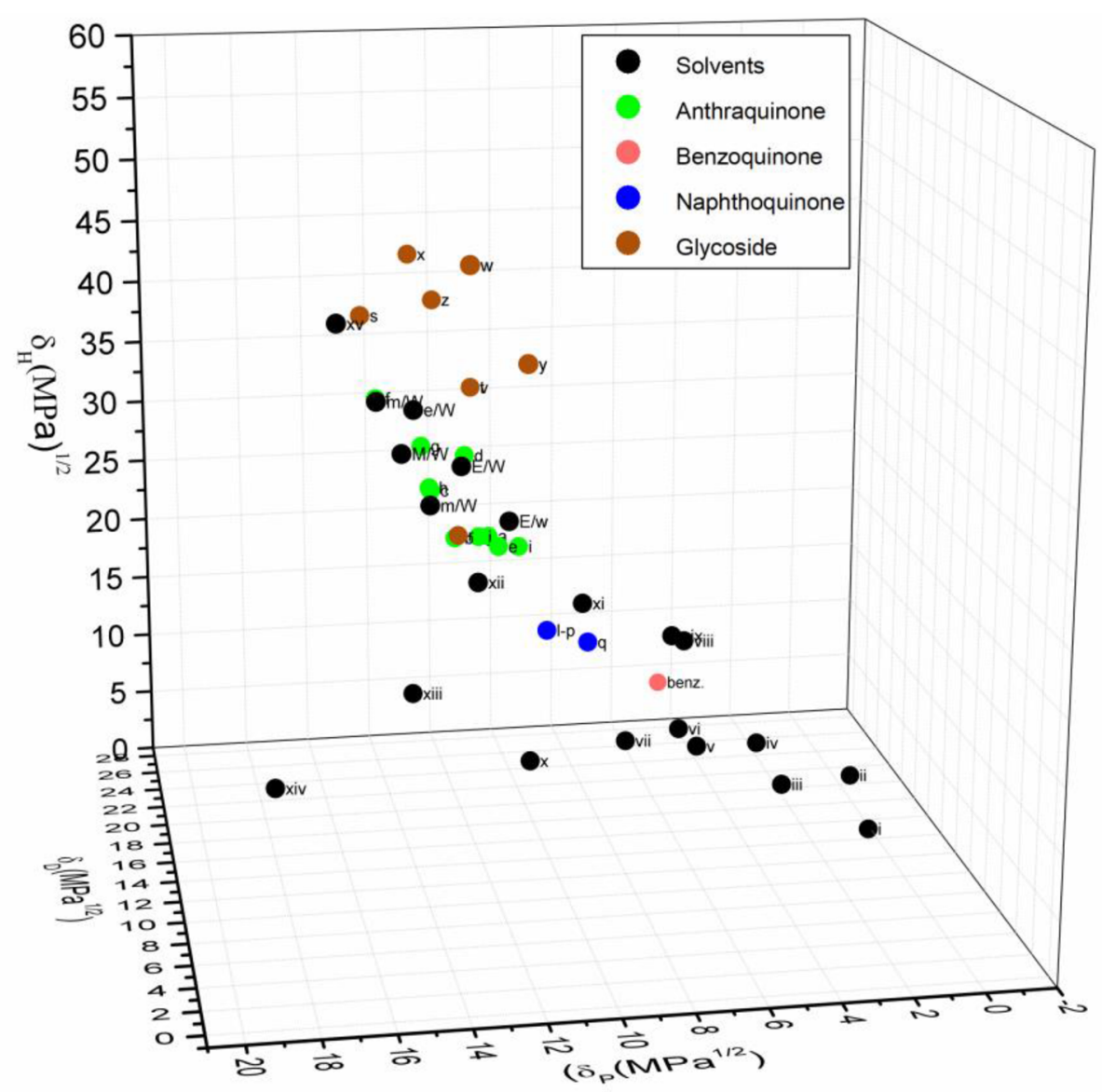

Key

$\begin{aligned} & \text { Solvents } \\ \text { i. } & \text { Hexane } \\ \text { ii. } & \text { Benzene } \\ \text { iii. } & \text { Diethyl ether } \\ \text { iv. } & \text { Chloroform } \\ \text { v. } & \text { Ethyl acetate } \\ \text { vi. } & \text { Tetrahydrofuran } \\ \text { vii. } & \text { Dichloromethane } \\ \text { viii. } & \text { Butanol } \\ \text { ix. } & \text { Propanol } \\ \text { x. } & \text { Acetone } \\ \text { xi. } & \text { Ethanol } \\ \text { xii. } & \text { Methanol } \\ \text { xiii. } & \text { Dimethylformamide } \\ \text { xiv. } & \text { Acetonitrile } \\ \text { xv. } & \text { Water } \\ \text { e/W } & 30 \% \text { Ethanol } \\ \text { E/W } & 50 \% \text { Ethanol } \\ \text { E/w } & 70 \% \text { Ethanol } \\ \text { m/W } & 30 \% \text { Methanol } \\ \text { M/W } & 50 \% \text { Methanol } \\ \text { m/W } & 70 \% \text { Methanol }\end{aligned}$

Anthraquinone

Alizarin

Aloe-emodin

Munjustin

d Marindone

e Physcion

f Pseudopurpurin

g Purpurin

h Rheum

i Rubidian

j Xanthopurpurin

Naphthoquinones

k Lawsone

m Alkannin

n Shikonin

n Juglone

o Lapachol

p Plumbargin

Benzo Benzoquinone
Glycosides

r Lucidin primeveroside

s Carminic acid

t Ruberythmic acid

u Quinizarin

v Emodin-8-o-glucoside

w Rhein-8-o-glucoside

x Chrysophanol-8-oglucoside

z Aloe-emodin-8-o-glycoside

Fig. 3 Hansen solubility of quinones using common solvents 


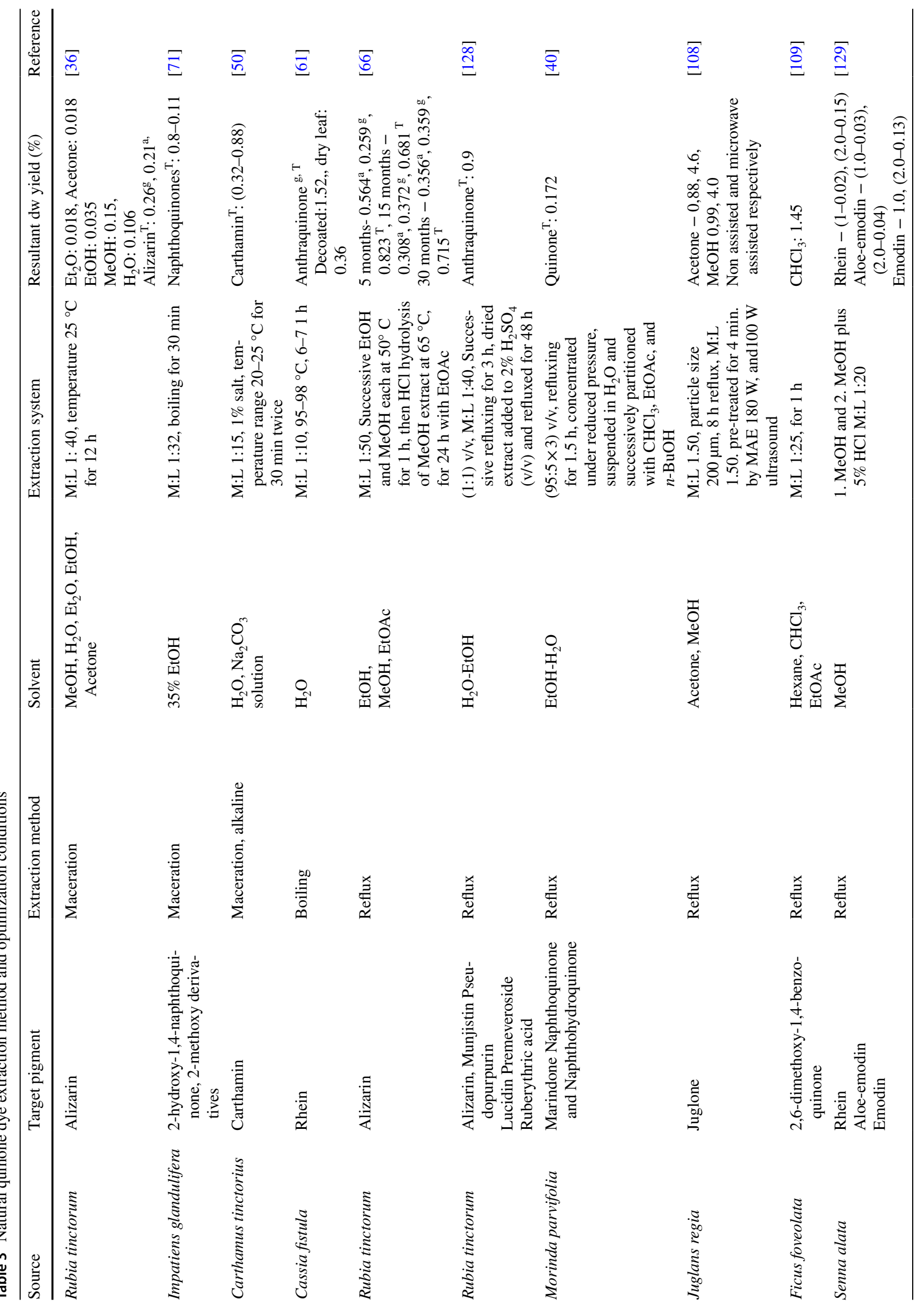




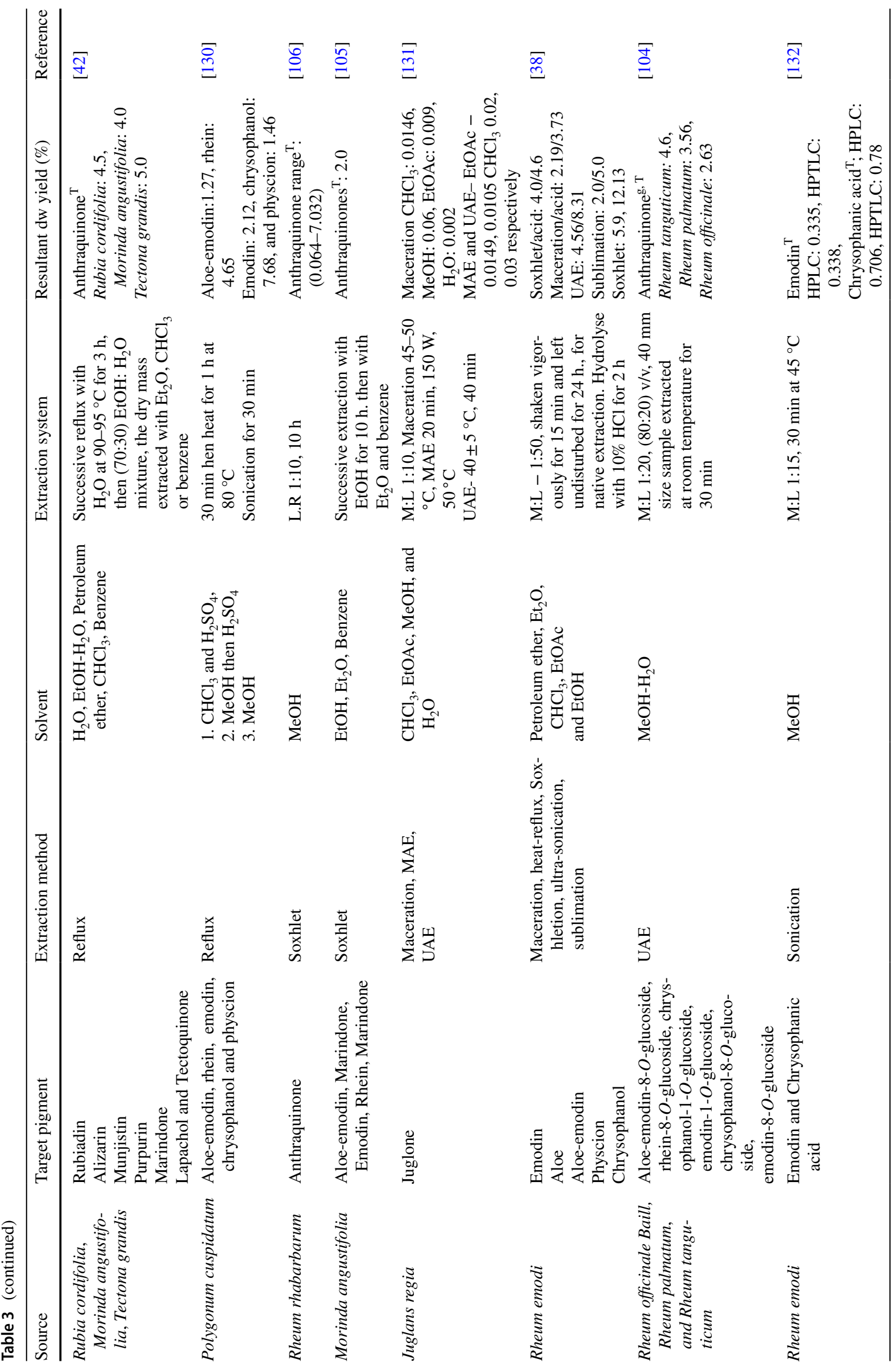




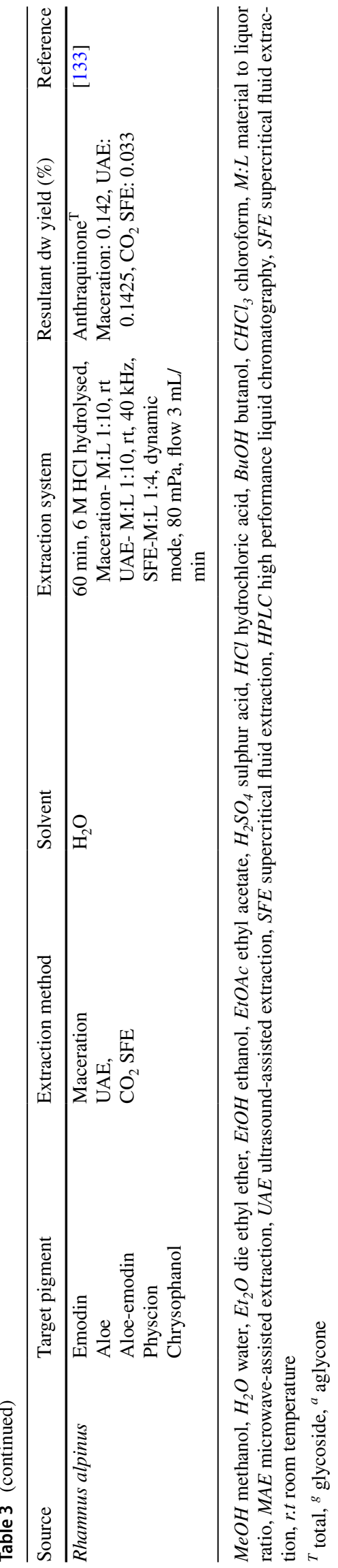

extracted along with their primeverosides (in the aqueous phase).

Another factor, the solid-liquid (S/L) ratio, is also important as this determines the interaction between the solute and solvent during the extraction. Table 3 shows that the $\mathrm{S} / \mathrm{L}$ ratio ranges from 1:10 to 1:50. Typically, this ratio also depends on other extraction parameters, such as the solvent type, the extraction time and the method used.

\section{Extraction Methods}

Methods applied for extracting quinones include maceration [116], reflux [117], Soxhlet [118, 119], microwave assisted [118, 120, 121], ultrasonic assisted [118, 122], ultrasonic-microwave assisted [123], enzyme assisted [37, 124], supercritical fluid [125], sublimation assisted [38], and pressurised liquid $[121,126]$ extractions. The applicability, requirements and results vary considerably among these methods.

Some of these extraction methods, such as static and dynamic maceration, Soxhlet and ultrasonic extraction using n-hexane solvent, were compared for quinone extraction from the stem bark of Diospyros anisandra [127]. Soxhlet extraction was the most efficient technique, as it gave the highest yield of total quinone content at $11.5 \mathrm{mg} / \mathrm{g} \mathrm{dw}$, compared to $5 \mathrm{mg} / \mathrm{g} \mathrm{dw}$ for dynamic maceration, $4.5 \mathrm{mg} / \mathrm{g}$ $\mathrm{dw}$ for ultrasound-assisted and $3.75 \mathrm{mg} / \mathrm{g} \mathrm{dw}$ for static maceration methods. The efficiency of Soxhlet extraction is attributed to the continuous renewal of the solvent, which promote effective diffusion. Similarly, Aditya et al. [38], compared the efficiency of non-conventional methods, such as ultrasonication and sublimation, with the more classical methods, such as maceration, reflux and Soxhlet, to extract R. emodi. Refluxing was the most efficient method, with a recovery rate of $77.9 \%$, whereas sublimation, ultrasonication and maceration achieved $53.32 \%, 51.79 \%$ and $37.31 \%$, respectively. The highest impurity levels were obtained with Soxhlet and maceration, while sublimation gave the most selective, cost effective and environmentally friendly results, with minimum infrastructural and solvent requirements [26, 38]. Reflux extraction requires less time and has also proved to be suitable for commercialisation [26]. On the same note, extraction efficiencies of supercritical, microwave-assisted, enzymatic, solid-liquid and conventional extraction methods have also been compared. Supercritical fluid extraction and pressurised liquid extraction required shorter extraction times and were more environmentally friendly, at a similar equipment and operating costs [26]. Extraction methods for different quinone pigments, the optimised conditions, and the obtained yield are summarised in Table 3 .

As indicated in Table 3, most researchers choose reflux, Soxhlet and maceration methods for quinone extraction, with yield and extraction time being the most considered 
parameters. While reflux and Soxhlet give comparatively high quinone yields, Soxhlet requires a long extraction time making it comparatively more expensive. Conversely, the maceration method is preferred for quinone extraction mostly in medical application areas. Thus, trading off the scale of extraction yield, extraction time and cost reveals that the reflux method is clearly the most cost-efficient extraction method for quinone dyes. Here, extraction temperature normally ranges around $90-98{ }^{\circ} \mathrm{C}$ for $60 \mathrm{~min}$.

\section{Purification}

Purification of the quinone crude extract is typically required to eliminate other interfering compounds. This separation is mainly achieved by methods such as thin layer chromatography (TLC) [134], high performance liquid chromatography (HPLC) [135] and phase separation [136]. Other methods include high-speed counter-current chromatography (HSCCC) [137], electrophoresis [106], and supercritical fluid chromatography (SCFC) [138].

TLC has long been used as a general procedure for separating quinones [32]. Generally, the TLC plate consists of a silica gel based stationary phase and a mobile phase containing a variety of eluents, typically mixtures of methanol, ethanol, water, chloroform, ethyl ether, acetate, toluene, hexane, ethyl acetate and propanol at different ratios. The TLC method separates lipid-soluble benzoquinones and naphthoquinones by carrying them along with the more nonpolar solvent mixture. At the same time, the complex and highly hydroxylated quinones require more polar solvent mixtures to mobilise them. The TLC method's main limitations are its slow speed and poor quality separation and difficult scalability. However, compared to other methods, it still shows advantages in terms of low equipment and consumables costs, as well as versatility in application [32, 48].

Compared to TLC, other chromatographic techniques show increased sensitivity and shorter purification times, but this comes with higher costs [139]. For chromatographic purposes, water-methanol-acetic acid, chloroform-methanol-formic acid or acetonitrile solutions are mostly used as eluents [26], although n-hexane-ethyl acetate-methanol-water or petroleum ether-ethyl acetate-water mixtures can be used in counter-current systems to give higher purities (>90\%).

A related method is SCFC, which is viewed as an environmental friendly method. Here $\mathrm{CO}_{2}$ is used as the mobile phase and just a little solvent, either directly or in reverse phase, has also been applied to clean up quinone extracts [138]. The use of $\mathrm{CO}_{2}$ permits a high flow and diffusion rate, thereby improving the selectivity and shortening the analysis time. Organic modifiers, mostly alcohols, are used to enhance dissolvability. However, based on the available literature, this technique is not commonly used for quinone purification.

Alternatively, two-phase separation methods and precipitation are also used [140, 141]. In two-phase separation systems, the phase combinations have included polyethylene glycol/dextran, polymer/salt polyethylene, glycol/sodium sulphate, and non-ionic surfactant micellar systems, such as Triton X-114 [136]. While the method's significant strength has been the simplicity of the equipment used [140], its main challenges have been the slow segregation and re-extraction from the polymer phase [142]. However, a low cost, low viscosity, easy recoverable system using an alcohol/salt two-phase system has also been proposed [142]. The latter used 1-propanol and $\left(\mathrm{NH}_{4}\right)_{2} \mathrm{SO}_{4}$ to purify anthraquinones extracted from Aloe vera. A phase ratio of 0.34 (17.84/26.66 concentration of alcohol/salt $\% \mathrm{w} / \mathrm{w})$, achieved a partition coefficient of 64 , and an extraction efficiency of $96 \%$ were achieved [142]. Another example has demonstrated phase separation of alizarin glycoside and aglycone from $R$. tinctorum extract $[113,143]$. The subsequent extraction with solvent from the Sep-Pak Plus silica has led to a recovery of 90-100\% for bacterial quinones, compared to the conventional recovery of about 30 to $60 \%$ obtained with column chromatography and TLC [144].

Solid phase extraction or solid sorption is also becoming more popular since the sorbent materials used are stable in a narrow $\mathrm{pH}$ range and are capable of extracting polar and/ or nonpolar compounds [145]. The main advantage of this method is the ability to separate the matrix from the target compound, automation ability, and ability to concentrate the final product [144]. Quinones have also been purified successfully by electrophoresis. For instance, the method was used to separate glycosidic quinone compounds from an extract of R. emodi [106]. The technique works well for an alkaline phase using a buffer and an ethanol, methanol or acetonitrile mobile phase. Compared with other liquid-phase analytical methods, the electrophoresis method is versatile, efficient and requires low amounts of solvent and reagent.

Quinones are known to have a high protein affinity [146], which means they can be separated by precipitating proteins from extract matrices [147]. The quinones are then recovered or separated from the protein-quinone complex through methods such as fractionation, centrifugal filtration and chromatofocusing [146, 148]. While purifying 1,4-benzoquinone, Brock et al. [149] reported purification of quinonones through protein removal using ammonium sulphate fractionation, hydrophobic interaction, ion-exchange and affinity chromatography. Anthraquinones extracted from Semen cassia were purified by first precipitating the extracted cassia powder with saturated ammonium sulphate at $4{ }^{\circ} \mathrm{C}$ for $10 \mathrm{~h}$, dialysing in deionised water and then recovering the anthraquinone by foam fractionation. A concentration of $94 \mathrm{mg} / \mathrm{L}$ was found in the foam, with a total recovery of 
more than 48\% [146]. A comparison of quinone purification techniques is provided in the Table $\mathrm{S} 1$.

From Table S1, suggests that HSCC may be a more appropriate method for quinone purification since the main limiting factor, namely the capacity of the column volume, is independent of the analyte itself and can be scaled up and automated to meet industrial dyeing demands. Its simplicity in terms of less sample preparation requirements, higher purity yield and total sample recovery also makes HSCCC comparably more economical for quinone purification. However, many of these techniques are analytical, rather than large-scale separation techniques. Therefore, further purification to yield a pure component would be a challenge industrially, also especially given the complexity of the quinone group.

\section{Chemical Analysis}

This section discusses various methods applied for quinones analysis. These include both qualitative and quantitative methods.

\section{Qualitative Methods}

Within this part, we mainly discuss phytochemical screening, which is a qualitative way to determine the presence of a group of compounds of interest. This type of analysis is often done by a colour reaction. For quinones, the success of these tests depends on one main distinctive property that distinguishes the quinone of interest from other typical colored compounds, which is the ability of quinones to undergo reduction and oxidation [20]. This property enables quinone molecules to be identified by reacting them with a range of reagents that generate different colours depending on the class of the quinones and/or position of hydroxyl groups on the benzoid ring. Important colour reaction tests are the Bornträger and alkaline reagent-based tests, which involve reaction of anthraquinones with an alkaline medium that results in production of their corresponding phenolate ion [150]. For example, the hydroxyls on 1,8-dihydoxyanthraquinones react with weak bases like ammonium hydroxide and are transformed into a phenolate ion. Anthraquinones having hydroxyls at positions 1 and 2 acquire a blue violet colour, whereas 1,8-disubstituted anthraquinones display a red colour [20]. Anthrones and dianthrones become yellow but rapidly oxidise to their corresponding anthraquinones to acquire red staining. The reaction mechanisms of anthraquinones are shown in Fig. 4a. For naphthoquinones and benzoquinones, an acid oxidation reaction (such as sulphuric or hydrochloric acids) gives a red or red-orange colour and is their preferred screening method (Fig. 4b).
Some quinones, especially those with C-glycosides, do not undergo hydrolysis when heated with dilute alkalis or acids. They are often screened by a modified Bornträger method, which involves heating with ferric chloride in hydrochloric or sulphuric acid medium to decompose them $[61,152]$. The glucoside is then extracted in a suitable organic solvent, such as benzene, tetrachloride, dichloromethane or chloroform. Next, the lower layer, in the case of chlorinated solvents, is separated and diluted with ammonia where development of pink or red colour in the ammonia layer confirms the presence of anthraquinones [61].

These screening methods are preliminary tests that should be supplemented by other qualitative analysis, since the colours obtained can be greatly influenced by cross conjugation and other structural features [20]. A summary of screening methods is presented in Table 4, which shows that Bornträger and alkaline based reactions are used to detect anthraquinones while acid-based reactions are used to screen benzoquinones and naphthoquinones.

\section{Quantitative Methods}

These methods are used to characterise and/or quantify quinones. They include titrimetric, chromatography, UV-VIS spectroscopy and other related methods.

\section{Titrimetry}

This technique is based on the compound's ability to undergo a reduction reaction, which is unusual among other organic compounds. The reduction is achieved by reacting quinones with reducing agents or through catalytic hydrogenation. Different titrimetric methods have been investigated for quinones determinations. These include visual [157, 158], potentiometric [159], voltammetry [160], and differential pulse polarography [161] techniques. Here, a reducing agent in an aqueous acidic medium is used to stoichiometrically titrate quinone. The success of these methods depends on reagents used. Generally, the use of titrimetric methods has drastically declined, perhaps due to the numerous limitations associated with them.

\section{Chromatography}

Here, equipment such as HPLC and TLC are normally coupled with various detectors such as ultraviolet visible (UV-Vis) [36, 135], diode array detector (DAD) [128], fluorescence (FL) [154], mass spectrometry (MS) [162], chemiluminescence (CL) [155] and electrochemical detector (ED) [156].

Apart from being a quinone purification tool, TLC alone has also been used to identify quinones [134]. For GC-MS quantification, the volatility and thermal stability 
<smiles>CC(C)O</smiles>

1,2-dihydroxyanthraquinone (red)<smiles>O=C1c2ccccc2C(=O)c2c1ccc([O-])c2[O-]</smiles>

Phenolate anion (blue-violet)<smiles>O=C1c2ccccc2C(=O)c2c([O-])ccc([O-])c21</smiles>

Phenolate anion (purple)<smiles>O=C1c2cccc([O-])c2C(=O)c2c([O-])cccc21</smiles>

Phenolate anion (red-orange)

a<smiles>O=C1C=C(O)C(=O)c2ccccc21</smiles>

2-hydroxy-1,4-napthoquinone

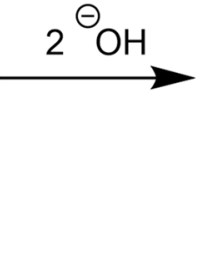<smiles>O=C1C=C([O-])C(=O)c2ccccc21</smiles>

b

orange-red

Fig. 4 Quinone colour reaction a Bornträger reaction [150], b pH-dependency of naphthoquinone compounds [151] 
of the quinone is required. The quinone volatility is typically increased by derivatisation through silylation to obtain trimethylsilyl (TMS)-derivatives of the respective quinones [163]. This is a complex procedure and can result in a biased quantification due to the effect of low vapor pressure and ionisation efficiency of the quinone [26, 164]. MS has been used to detect juglone, plumbagin and maritinone from plant extracts after derivatisation [108, 127], as well as munjistin and pseudopurpurin from $R$. tinctorum [128] and anthraquinones from Fusarium oxysporum [134].

Quinones also undergo electrochemical reactions, making them suitable for analysis by ED. Electrochemical activity causes quinones to produce electromagnetic radiation when excited, so CL is also applicable. These methods are more selective, sensitive and rapid compared to MS, but they are limited by a tendency for oxidation of the analyte by the dissolved oxygen from the mobile phase, which is mediated by degassing the instrument [164]. Methods like MS and $\mathrm{CE}$ also require that the quinone analyte be ionised, which can complicate the procedure especially when a buffer is required [26].

Important quinone identification method are shown in Table 4, which demonstrates that each analytical method can be used to characterise any class of quinone. Furthermore, these analytical methods can detect both glycosylated and aglycone quinones. Figure 5 gives an overview of the different methodologies for analysing quinones based on the appearance of the molecule. It shows that photoreaction,

Table 4 Quinone molecule screening and other analytical methods

\begin{tabular}{|c|c|c|c|c|c|c|c|c|c|}
\hline \multicolumn{5}{|c|}{ Qualitative methods } & \multicolumn{5}{|c|}{ Quantitative methods } \\
\hline $\begin{array}{l}\text { Quinone com- } \\
\text { pound }\end{array}$ & $\begin{array}{l}\text { Born- } \\
\text { träger[150] }\end{array}$ & $\begin{array}{l}\text { Modified } \\
\text { Bornträger } \\
{[61]}\end{array}$ & $\begin{array}{l}\text { Bases }(\mathrm{NaOH}, \\
\mathrm{NH}_{4} \text { sol., } \mathrm{H}_{2} \mathrm{O}_{2} \text {, } \\
\left.\mathrm{KOH}, \mathrm{Mg}(\mathrm{Ac})_{2}\right) \\
{[153]}\end{array}$ & $\begin{array}{l}\text { Acids } \\
\left(\mathrm{H}_{2} \mathrm{SO}_{4} /\right. \\
\mathrm{HCl})[153]\end{array}$ & $\begin{array}{l}\text { Chroma- } \\
\text { tography } \\
{[36]}\end{array}$ & $\begin{array}{l}\text { Fluores- } \\
\text { cence } \\
{[154]}\end{array}$ & $\begin{array}{l}\text { Chemilu- } \\
\text { minescence } \\
{[155]}\end{array}$ & $\begin{array}{l}\text { Electro- } \\
\text { chemical } \\
{[156]}\end{array}$ & $\begin{array}{l}\text { Structural } \\
\text { analysis [26, } \\
105]\end{array}$ \\
\hline Anthraquinone & $\mathrm{x}$ & $\mathrm{x}$ & $\mathrm{x}$ & - & $\mathrm{x}$ & $\mathrm{x}$ & $\mathrm{x}$ & $\mathrm{x}$ & $\mathrm{x}$ \\
\hline $\begin{array}{l}\text { Naphthoqui- } \\
\text { none }\end{array}$ & - & - & - & $\mathrm{x}$ & $\mathrm{x}$ & $\mathrm{x}$ & $\mathrm{x}$ & $\mathrm{x}$ & $\mathrm{x}$ \\
\hline Benzoquinone & - & - & - & $\mathrm{x}$ & $\mathrm{x}$ & $\mathrm{x}$ & $\mathrm{x}$ & $\mathrm{x}$ & $\mathrm{x}$ \\
\hline
\end{tabular}

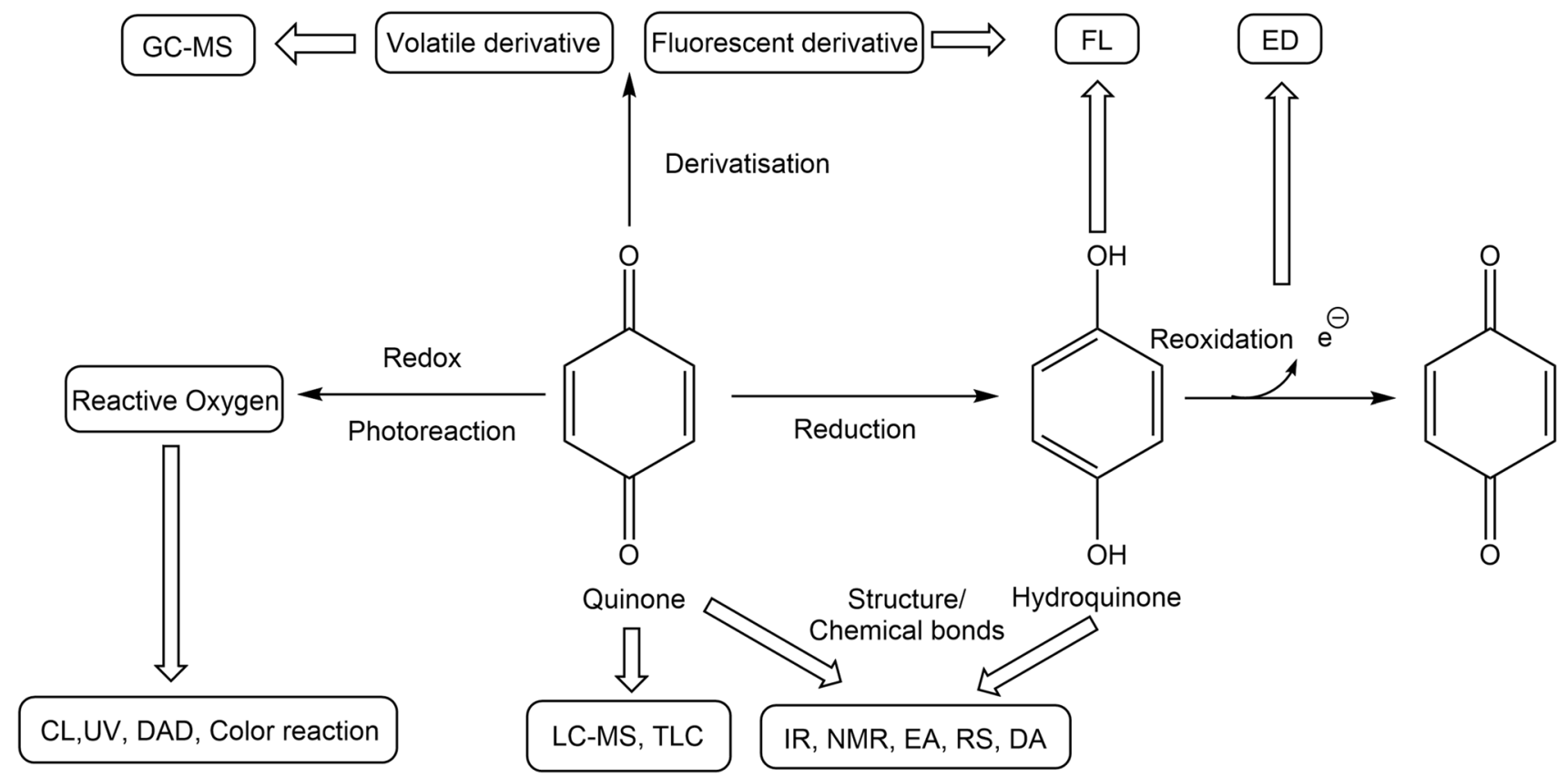

Fig. 5 Analytical methods for quinone compound. Modified from Naoya, Naotaka [164]. Key: GC-MS—gas chromatography coupled mass spectroscopy, FL-fluorescence detection, ED-electrochemical detection, IR-infrared, NMR—nuclear magnetic resonance,
EA-elemental analysis, DA—degradation analysis, CL-chemiluminescence, LC-MS—liquid chromatography mass spectroscopy, TLC - thin layer chromatography, UV-ultraviolet, DAD-diode array detection 
electrochemical reaction-oxidation, derivatisation, chemical bond vibration, light absorption in the UV-Vis region, and mobility in the mobile phase are important properties for quinone analyses.

\section{UV-Vis Spectroscopy}

This is a method that makes use of the conjugated system in the quinone structure that absorbs specific wavelengths in the UV-Vis region. However, quinone derivatisation is sometimes necessary to enhance the peak absorbance [165]. The peaks formed are compared to those of known quinone standard compounds for identification. According to Harborne [32], all coloured benzoquinone spectra show two peak, one strong peak at $260-290 \mathrm{~nm}$ and a weak one at $375-410 \mathrm{~nm}$. The spectra of all coloured naphthoquinones also characteristically display three to four peaks; one or two peaks below $300 \mathrm{~nm}$, one peak at 330-340 nm and one peak above $400 \mathrm{~nm}$, while all coloured anthraquinones typically show four to five peaks within the visible region; one peak above $430 \mathrm{~nm}$ and the rest below $300 \mathrm{~nm}$. Note, however, that the peak positions depend on the solvent used.

UV-Vis measurement have also been used for quantification of quinones. Here again, derivatisation might be necessary, and the success of a derivatisation reaction depends on the reagents used. Reagents such as methanol have been investigated as a quinone derivatisation agents to quantify p-benzoquinone, methyl-p-benzoquinone, 1,2-naphthoquinone, 1,4-naphthoquinone and 1,4-naphthoquinone, but the derivatisation process takes time to complete [162]. Analine was used as a reagent, but it only derivatised p-benzoquinone and chloranil quinone compounds [166]. Phenazine reagent has also been used [165], though, it only shows selectivity for benzoquinones and not to naphthoquinones and anthraquinones. A seemingly better derivatising reagent is piperidine [167]. The derivatization method is simple, sensitive, selective and can give $96 \%$ recovery. Another spectrophotometric method for determining quinones (1,4-benzoquinone, 1,4-naphthoquinones and p-chloranil) in 50\% methylalcohol-water mixture solvents is their derivatisation by 1,3-dimethylbarbituric acid [168] and barbituric acid [169]. The advantage of this method is its increased sensitivity and colour stability. Anthraquinones have also been quantified after derivatising with alkaline reagents (Fig. 4a), such as $\mathrm{NaOH}$ containing $2 \% \mathrm{NH}_{3}$ [170], 5\% magnesium acetate [61, 171], and ferric chloride [129], among others.

Using the UV-Vis method, the quantity of quinone can be determined via external calibration, i.e. a validated linear relationship between absorbance and quinone content, developed with a pure or standard quinone compound [66]. In addition to quinone quantity, the developed calibration curve can be used to determine the linear range, LOD and LOQ of the quinone extract using methods like the signal-to-noise ratio [109]. The advantage of using quinone standards is the high accuracy and the ability to simultaneously identify and quantify quinone compounds. Many quinone standards are commercially available like alizarine, purpurin, quinizarin, 2-hydromethylanthraquinone, 1,8-dihydroxyanthraqionone, 2,6-dihydroxyanthraquinone [128], p-benzoquinone, methyl-p-benzoquinone [162], aloe-emodin, chrysophanol, physcion, rhein, emodin [38, 172], juglone and lawsone [173], among others. However, the array of different standards required and the high cost involved, limits the use of these standards [106].

\section{Other Analytical Methods}

Other methods include IR spectroscopy [105], nuclear magnetic resonance (NMR) [42, 134], elemental analysis (EA) [42, 105], degradation analysis (DA) [105] and Raman spectroscopy (RS) [174]. IR analysis always presents a high and a low intensive bands. For 1,2-benzoquinone and 1,4-benzoquinone, the high intensity bands are shown at $300-1650 \mathrm{~cm}^{-1}$ whereas the low intensity band appears at $\sim 3200 \mathrm{~cm}^{-1}$. For 1,4-naphthoquinone, the most intensive peaks lie in the region from $\sim 700$ to $1800 \mathrm{~cm}^{-1}$ while a low band is found at $\sim 3200 \mathrm{~cm}^{-1}$. For 9,10- anthraquinone, the intensive peaks fall in the region from $\sim 400$ to $1810 \mathrm{~cm}^{-1}$, and a less intense peak appears around $3300 \mathrm{~cm}^{-1}$ [175]. In most cases, only the principal band is being stated.

FT-IR spectroscopy is used to define the presence and absence of functional groups, and NMR spectroscopy can then be used to identify the organic structure of the compounds. Thus, these two methods are complementary and can be used together [105]. Compared to UV-VIS and FTIR, the use of NMR and GC-MS or LC-MS requires far more expensive equipment and the methods are more complex. On the other hand, normal RS and enhanced surface spectroscopy are used more to analyse quinone dyes in artefacts $[176,177]$. Other methods, such as EA, DA or colourimetric techniques, and RS have been used but are not common thus are not discussed here.

The qualitative and quantitative methods for analysing natural quinones are summarised in Table 5, while characteristics used for their identification are given in Table 6.

Table 5, indicates that HPLC and UV-VIS are the preferred quinone identification and quantification techniques. A big advantage of HPLC is that it does not require quinone derivatisation. For UV-Vis, the use is justified since the method is simple, fast and sensitive [165]. IR and NMR are also popular especially where structural elucidation is required. 


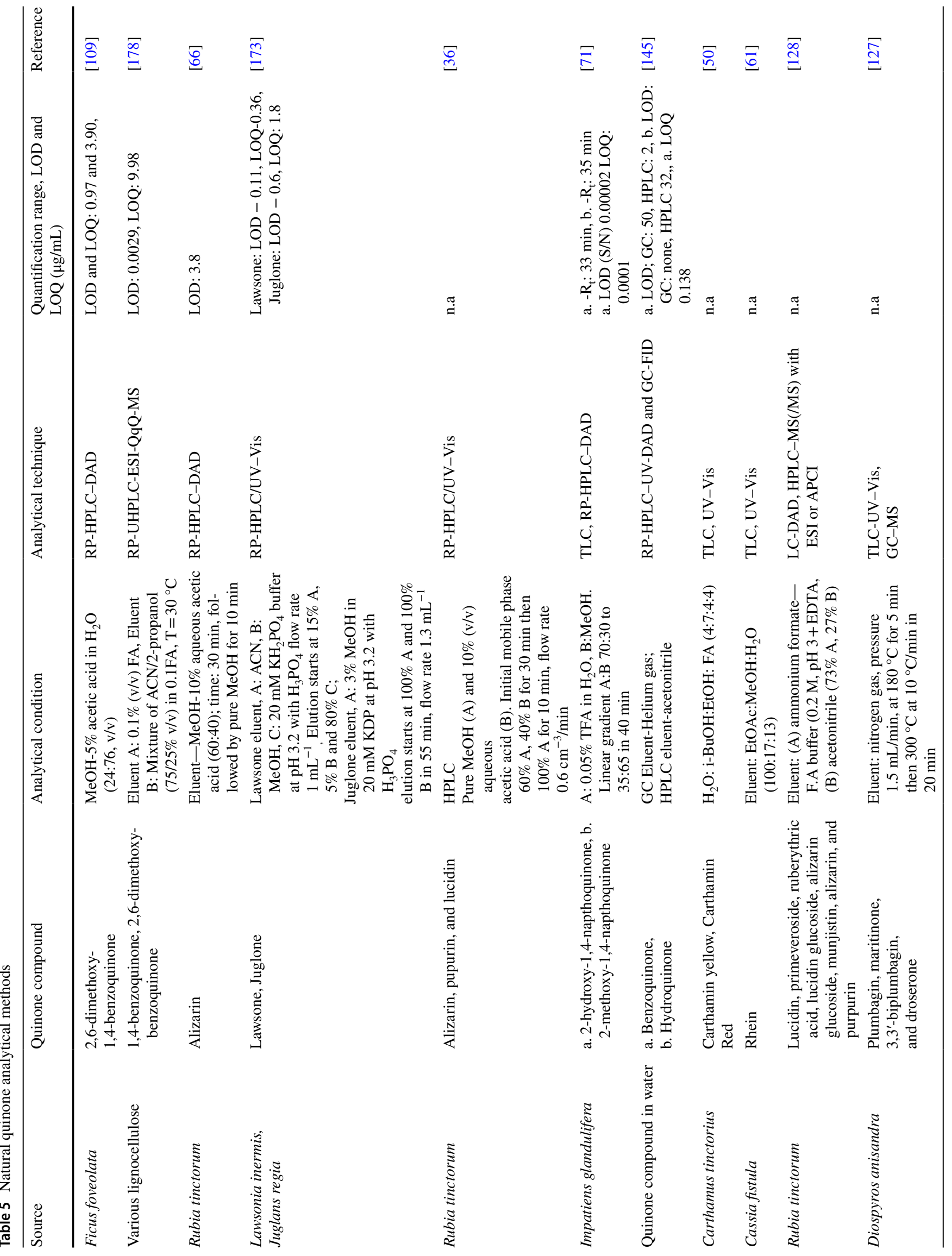




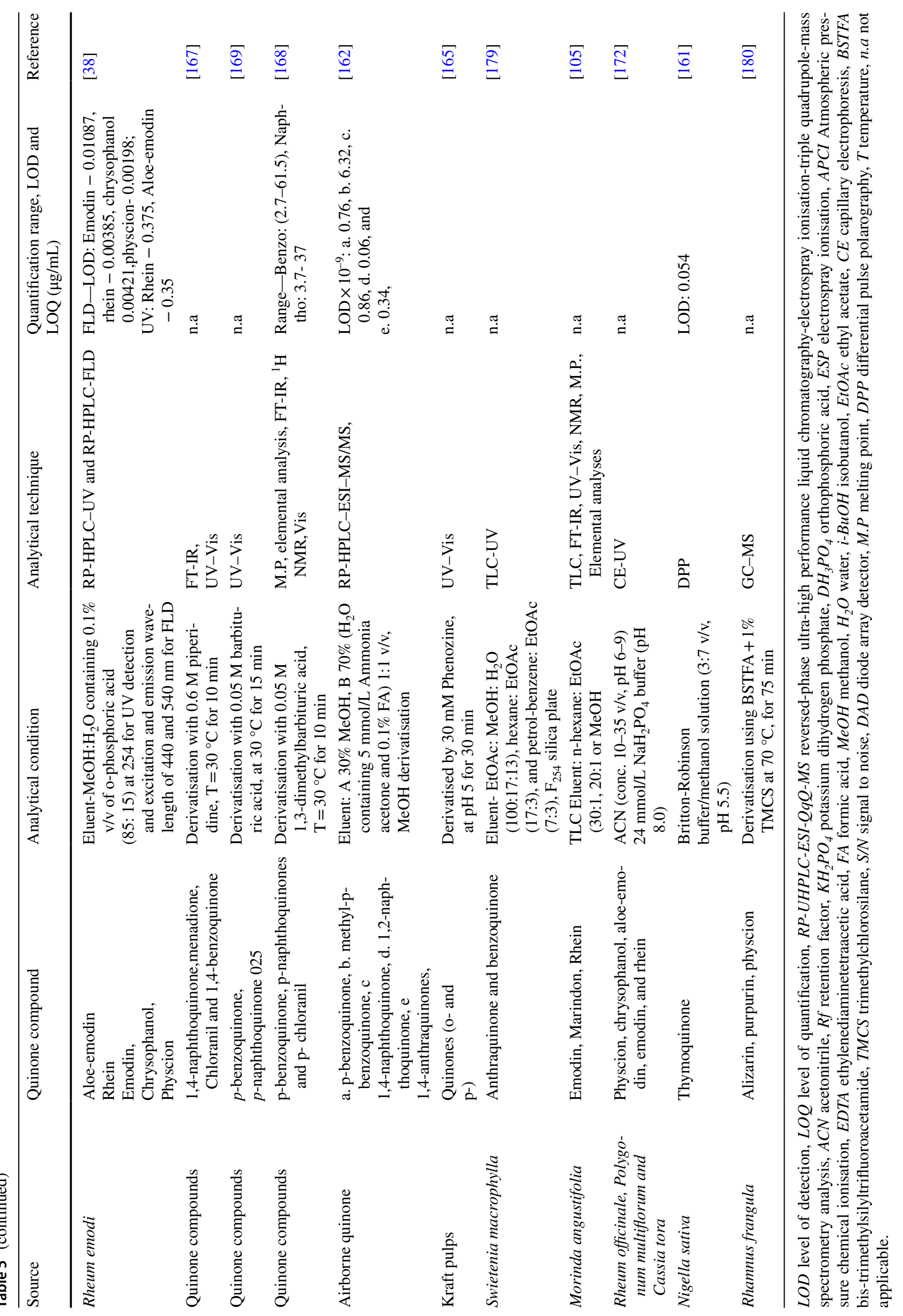




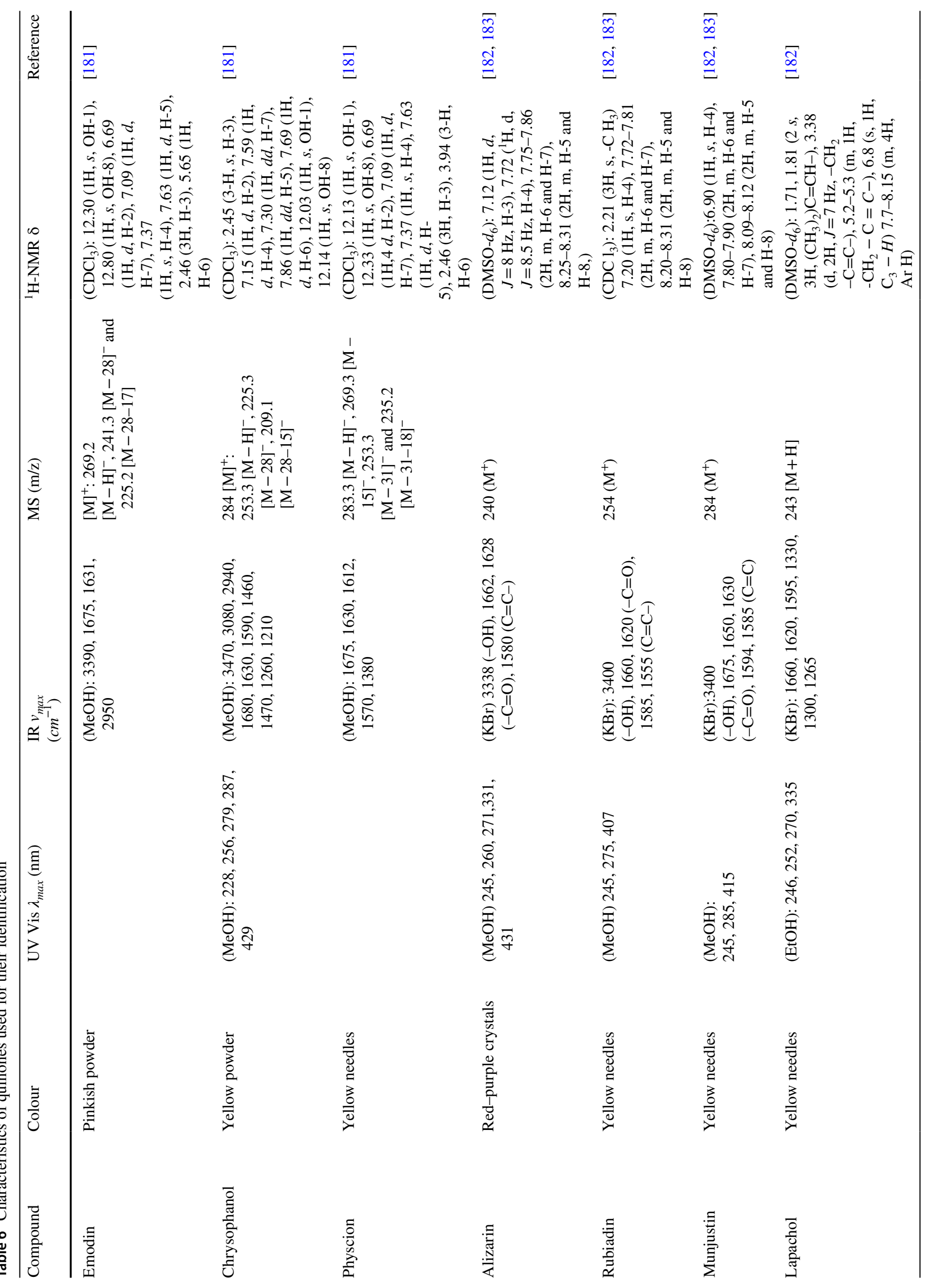




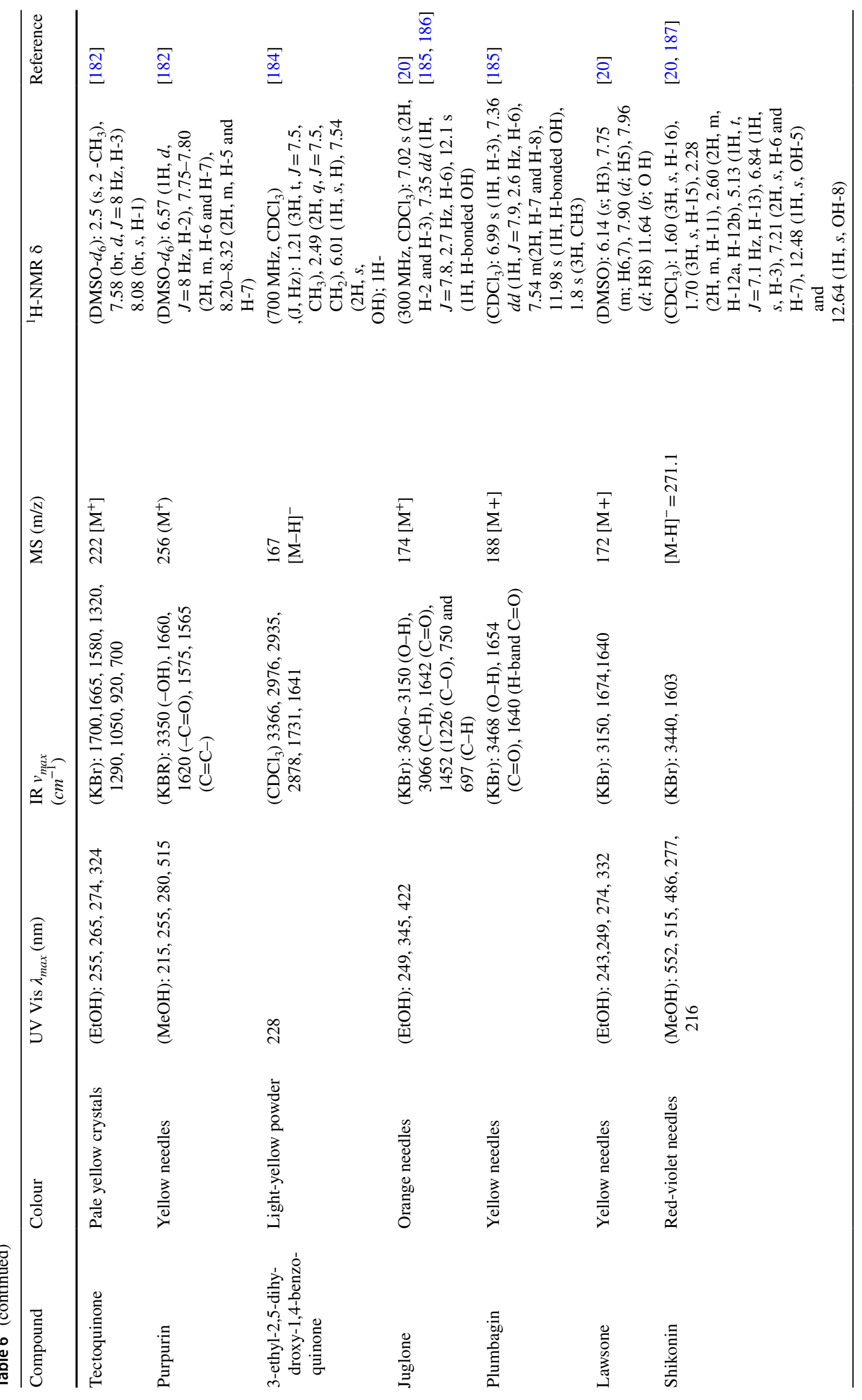




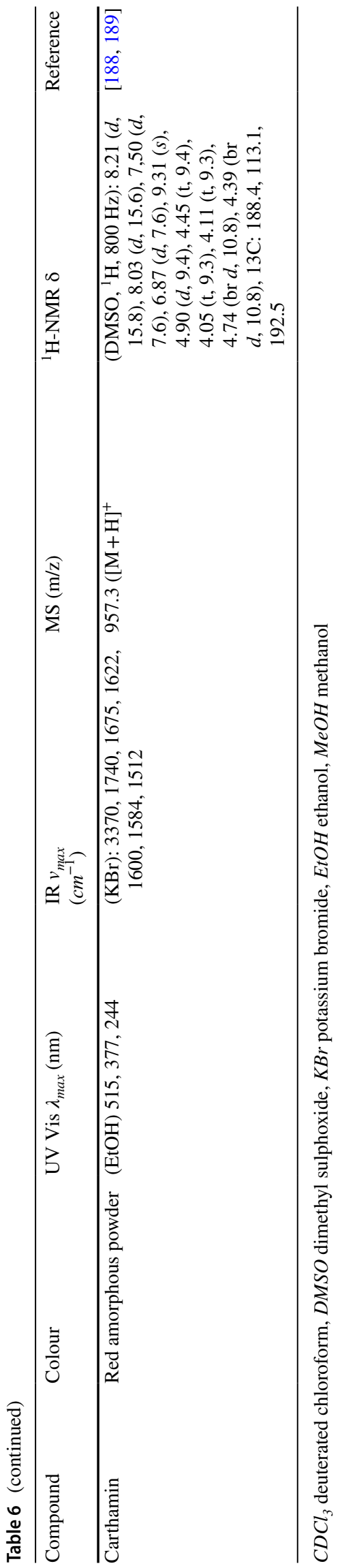

\section{Applications of Natural Quinone Dye}

Quinone dyes have been used for various applications, such as histological staining, rust prevention on metal surfaces, and increasing the conversion efficiency of solar cells, and they have found use as sensors, $\mathrm{pH}$ indicators, pigments, inks and dyes for leather, wood, medicine, food and textiles $[5,64,65,190,191]$. Of these uses, the most popular one is colouration of textiles, whereas their application in bio-inspired systems for energy harvesting and storage is a more recent development. Natural quinones are used at the industrial scale to colour both natural (vegetable/cellulosic, animal/protein and mineral) and synthetic (regenerated and fully man-made) textile fibers. In energy harvesting and storage, they are applied in areas such as artificial photosynthetic platforms and dye-sensitised solar cell etc. [192]. The areas of applications of natural quinones are summarized in Table 7. Dyeing methods, substrates, mechanisms, conditions and results (such as colour fastness, colour strength, dye uptake and dyeing kinematics) are given.

Table 7 confirms that all common and important natural fibres, such as cotton, wool and silk, can be dyed with quinones. For synthetic fibres, polyester and nylon have been successfully dyed using quinone dyes. Other items of interest that can be dyed with quinone dyes are hair, leather and wood, among others. These substrates can successfully be dyed through the conventional exhaustion dyeing method, without the need of a mordant. The substrates are normally dyed at $\mathrm{pH} 3-8$. For most substrates, the best dyeing temperature ranges between 90 and $100{ }^{\circ} \mathrm{C}$. However, polyester dyes best at a higher temperature $\left(130{ }^{\circ} \mathrm{C}\right)$. Most dyeing procedures give optimal fastness after one to $2 \mathrm{~h}$ of dyeing. Generally, dyeing results show high dye absorption and colour strength with or without mordants or substrate surface treatment, for all the substrates, although normally, lower substativity is experienced when natural quinones dyes are used to colour cellulose based substrates as compared to non-cellulose substrates. Besides, good fastness to, wash, perspiration and rubbing (3-5) and light (7-8) are achievable as well. Additionally, just like using synthetic dyes, similar dyeing methods can be adopted, with similar dyeing parameters and similar dyeing substrates giving acceptable results.

Typically, many colour shades can be obtained when natural quinone dye is used to colour textiles. The shades obtained can be further modified by use of mordants to obtain an even wider colour spectrum. Colour modifications occur as a result of the coordinate covalent bonds formed between the dye molecule, mordant, and fibre (Figs. 6 and 7). In fact, it has been reported that when using natural alizarin dyes and different mordants, all colours are achievable except dark blue [196]. When wool fibre was dyed with Rheum dye, the final colour was yellow. However, orange 


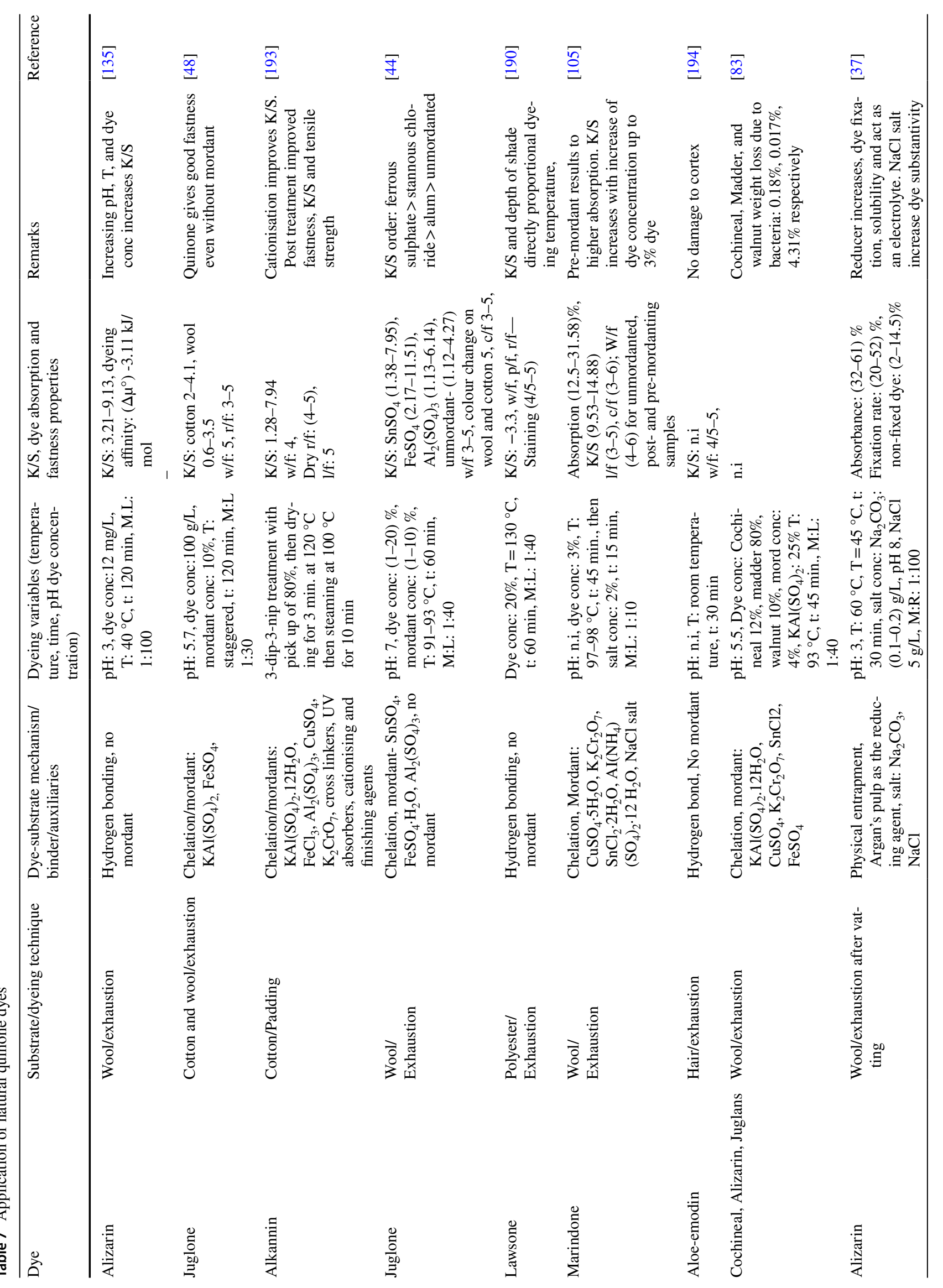




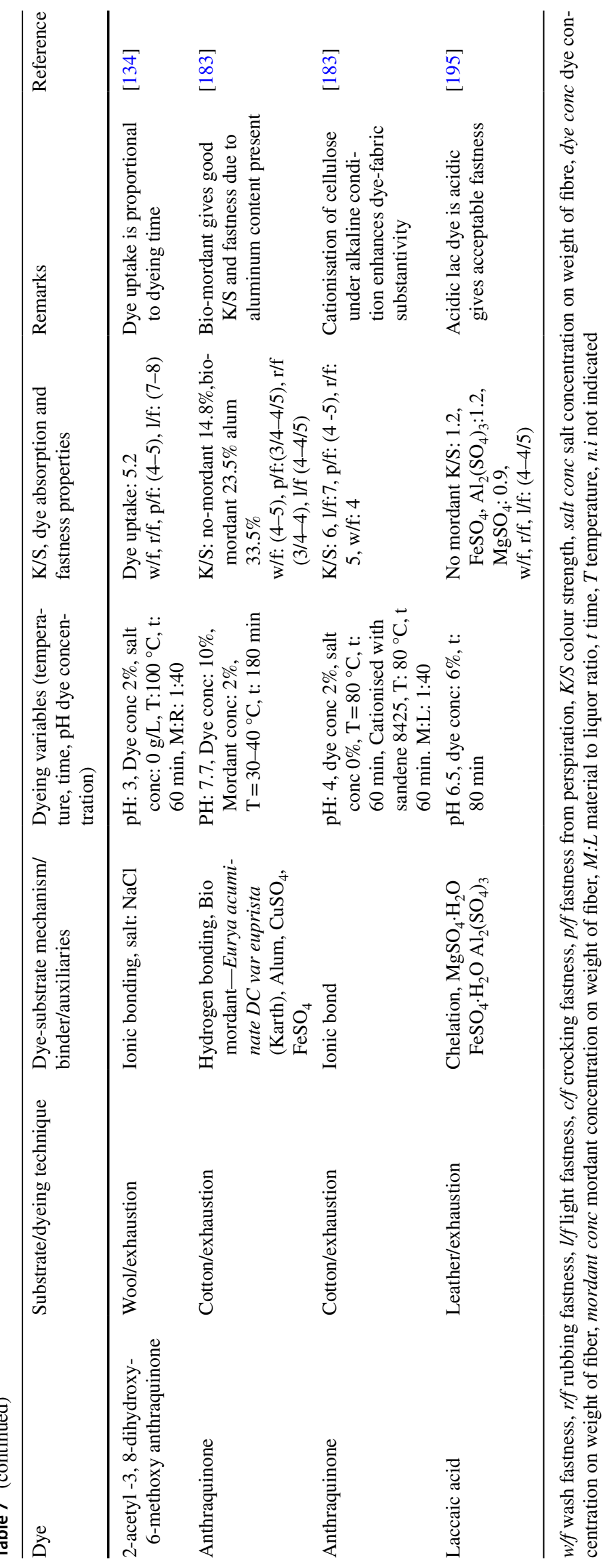


was obtained with alum as a mordant, while a chromium mordant retained the yellow colour [73]. Unmordanted alizarin gave a reddish-yellow colour on cotton and wool, while mordanting with alum gave cotton a dominant red colour and wool became pinkish [36]. Alizarin also gave yellow to purple colour on cotton after a vatting procedure, but this depends on the dyeing $\mathrm{pH}$ [37]. Juglans dyes gave a pinkish colour on non-mordanted wool but use of iron sulphate and stannous chloride mordant gave red and yellow colours, respectively [197]. Alkanet raw extract gave a greenish colour on cotton but a greyish and brownish colour when the same substrate was post-mordanted with $\mathrm{CuSO}_{4}$ and alum respectively [193]. Angelini et al. [66] also reported a red colour on cotton, a rose/pink colour with silk and a red/rose colour with wool yarns when $R$. tinctorum anthraquinonone dye extract was used with alum mordant. Thus, almost all colours are attainable when natural quinone dyes are used to colour substrates. The dye-substrate dyeing mechanisms involved are explained below.

\section{Cellulose-Based Fibres}

Cellulosic polymer structures Fig. 6a. have hydroxyl groups $(-\mathrm{OH})$ as the bonding sites responsible for attraction of dye molecules into the fibre [97]. However, cellulosic fibres have low substantivity to the natural quinone colorants resulting in poor dye affinity [29]. This limitation occurs due to the polar nature of cellulose and the varied polar quinone dyes inhibiting stronger dye-cellulose bonding, as well as the complexity of their molecules limiting dye diffusion [99]. To improve their substantivity, a number of techniques have been proposed. The use of mordants is the main technique<smiles>CC(C)(C)OC(O)C(CO)C(O)C(O)OC(O)C(O)C(C)(C)CO</smiles>

a

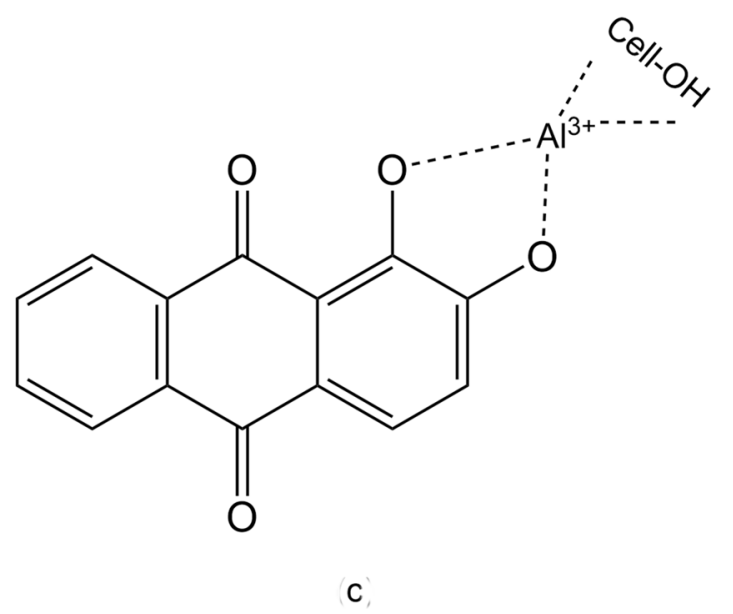<smiles>O=C1c2ccccc2C(=O)c2c1ccc(O)c2O[Al+2](O)I</smiles>

b

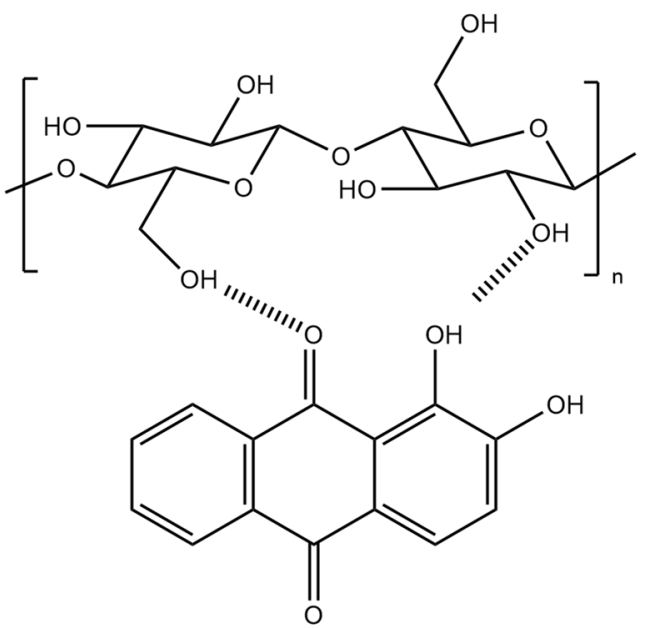

d

Fig. 6 Cellulose bonding a cellulose fibres structure [97], b chelation with carboxyl and hydroxyl, c chelation with di-hydroxyl moieties [183, 199], d hydrogen bonding [200]. Cell-OH represents the cellulose fibres 
that has been extensively studied [29] and have included aluminium sulphate, copper sulphate, ferric chloride and potassium salts. Due to environmental and health issues, the use of alum and iron sulphate is encouraged [29, 36, 48] since they are less toxic than other mordants [36]. Vankar et al. [183] investigated the quinone-metallic salt mordantcellulose bonding mechanism and proposed the formation of an insoluble dye-mordant coordination complex between alizarin and alum that generated a chelate ring with aluminium. The chelation was presumed to occur at two sites, one at the carbonyl and hydroxyl groups (Fig. 6b) and the other with di-hydroxyl moieties (Fig. 6c), and this formed coloured lakes capable of resisting stripping by water or organic solvent from cellulose substrates. The large dye structures also get entrapped within the complex cellulose, structure further enhancing the chelation. The use of biomordants, such as tannin [105], karth (Eurya acuminata DC var. euprista) [183] and Acacia catechu [198] has also been studied and the results suggest the same bonding mechanism $[183,199]$, with improved overall colour fastness and dye uptake [198].

Quinone dyes could also adhere to cellulose fibre structures through hydrogen bonds formed between the hydrogen or oxygen atoms of the dye and the oxygen and hydrogen atoms of the cellulose hydroxyl groups [200], as depicted in Fig. 6. However, since quinone dyes and cellulose fibers bear the same overall negative charge, a repulsion occur between the anionic dye and the fibres's negative surface potential, thereby reducing bonding efficiency. Different techniques have been suggested to mitigate against this effect. A case in point is the use of salts, such as $\mathrm{Na}_{2} \mathrm{SO}_{4}$ and $\mathrm{NaCl}$, to overcome the repulsion [190]. Higher dye exhaustions were observed with increasing salt concentrations. Even so, the method is not popular due to the potential negative impact on the environment. Similarly, fibre surface modification by cationisation methods has been studied [183, 201], and cellulose becomes positively charged and forms ionic bonds with the anionic dyes. The mechanism has been explained to involve substitution of several -OH groups of cellulose through grafting with the cationic agent [202]. The process has challenges, however, such as high cost, inadequate reactivity, fabric yellowing, excessive fabric tendering and toxicity. Nevertheless, this mechanism improves the dyeability of cellulose by quinone dyes. The cationised surface increases the wash fastness when compared to an untreated surface. The simultaneous use of both cationisation and mordanting processes further improves the cellulose fastness properties [203].

Other surface treatment methods, including UV-irradiation [204], oxygen plasma treatment [205], enzyme pretreatment [206] and biomimetic procedures [207] have been used mostly to improve substantivity, dye strength, dye uptake and colour fastness to washing, rubbing and light. However, the surface modification methods are complex and give inferior results compared to mordanting [193].

\section{Protein-Based Fibres}

Silk and wool are the most important protein-based textile fibres. Their properties such as the ionic nature, are influenced by their carboxylic and amino groups (Fig. 7a) and the sequence and bonding of the groups within the protein chain. Generally, protein fibres are resistant to dilute acidic conditions. They react with dilute acids to protonate an amino group $\left(-\mathrm{NH}_{3}^{+}\right)$, which can easily attract anionic quinone dye molecules through an ionic bond (Fig. 7b) [151].

Compared to cellulose, protein fibres have better substantivity for quinone dyes due to the strong dye-fabric ionic bond formed between the cationic fibre and the anionic dye [209]. Further improvement in color fastness and modifications in the color shade can be achieved with metallic mordants, such as potassium aluminium sulphate $\left[\mathrm{KAl}\left(\mathrm{SO}_{4}\right)_{2} \cdot 12 \mathrm{H}_{2} \mathrm{O}\right]$, copper (II) sulphate $\left(\mathrm{CuSO}_{4}\right)$, potassium dichromate $\left(\mathrm{K}_{2} \mathrm{Cr}_{2} \mathrm{O}_{7}\right.$ ) tin (II) chloride $\left(\mathrm{SnCl}_{2}\right)$, iron (II) sulphate $\left(\mathrm{FeSO}_{4}\right.$, copper(II) sulphate pentahydrate $\left(\mathrm{CuSO}_{4} \cdot 5 \mathrm{H}_{2} \mathrm{O}\right)$ and tin(II) chloride (II) dihydrate $\left(\mathrm{SnCl}_{2} \cdot 2 \mathrm{H}_{2} \mathrm{O}\right)$ Bio-mordants (the bonding mechanism is shown in Fig. 7c), such as gallnut (Quercus infectoria), pomegranate peel (Punica granatum), babool (Acacia nilotica) and chitosan, have also been used with remarkable improvement of colour fastness and shade reproducibility $[83,210]$. Moreover, as with cellulosic fibres, attempts have also been made to modify the protein fibres surface to further improve quinone dyeing. The effect of acid pretreatment on dyeing performance of walnut (the naphthoquinone juglone) dye on wool fibres has been studied [211]. The results showed better colour strength and fastness to washing, rubbing, and light when the substrate was pretreated with citric acid. Exhaustion after vatting of quinone dyes has also been used for coloring of textiles [37]. This technique showed a higher degree of dye fixation and wash fastness compared to the conventional exhaustion method, thereby increasing the anthraquinone substantivity for all types of textiles.

\section{Synthetic Fibres}

Nylon and polyester are the most important synthetic fibres coloured by quinone dyes [212, 213]. Acrylic and regenerated fibres, such as cellulose acetate, viscose and rayon, have also been dyed using natural quinone dyes [214, 215].

Nylon fibre is made primarily of a polar amide group (-CO-NH-) and amino groups $\left(-\mathrm{NH}_{2}\right)$. Absorption of quinone dyes is enabled by these amino groups, which are 


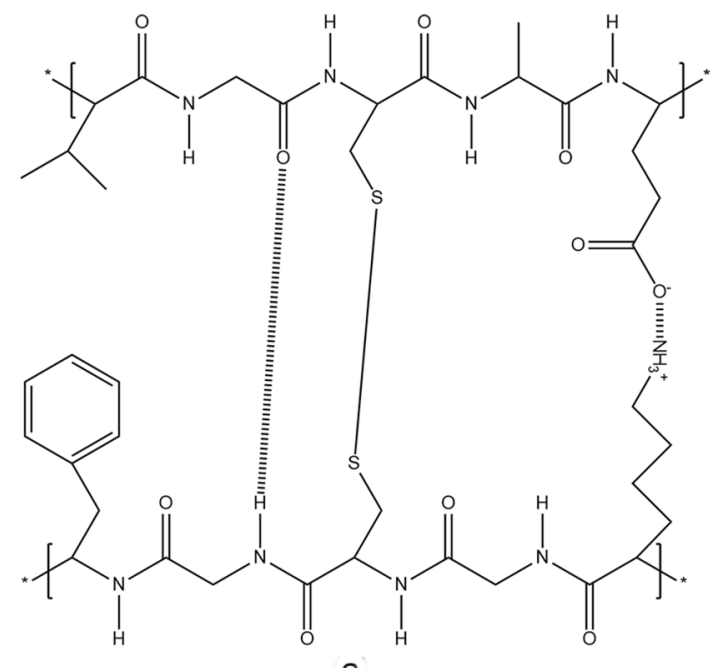

a

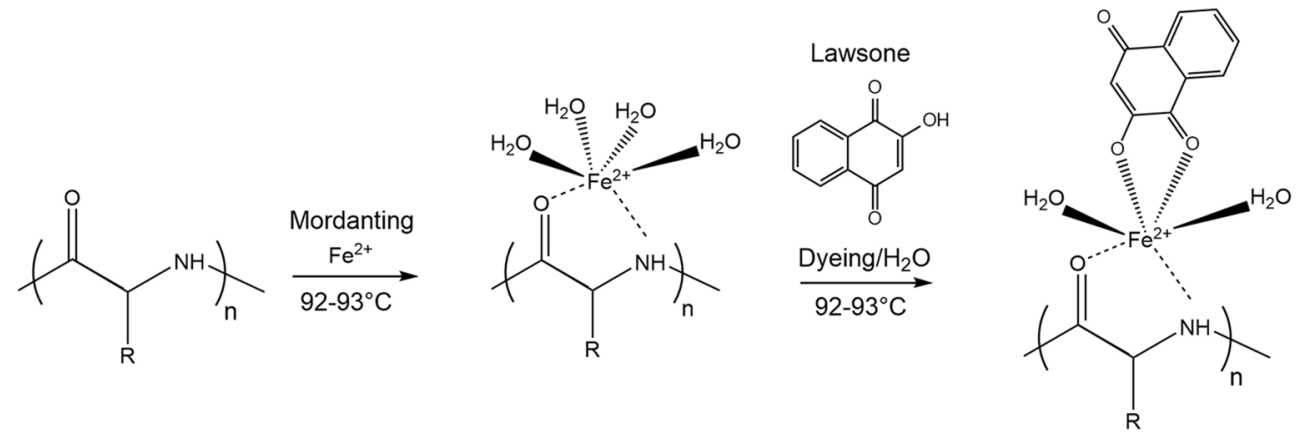

b
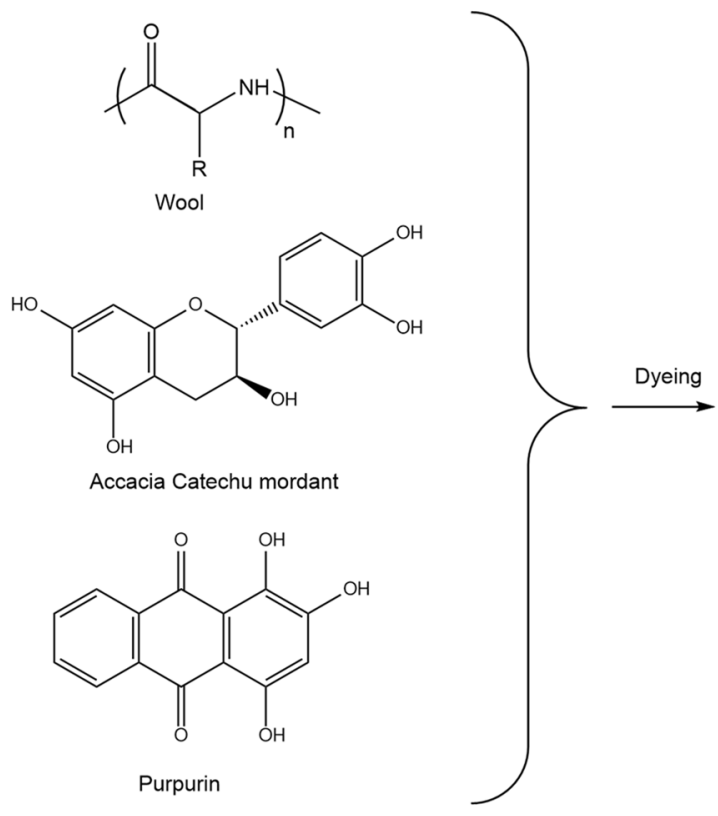<smiles>O=C1c2ccccc2C(=O)c2c(O)c(O)cc(O)c21</smiles>

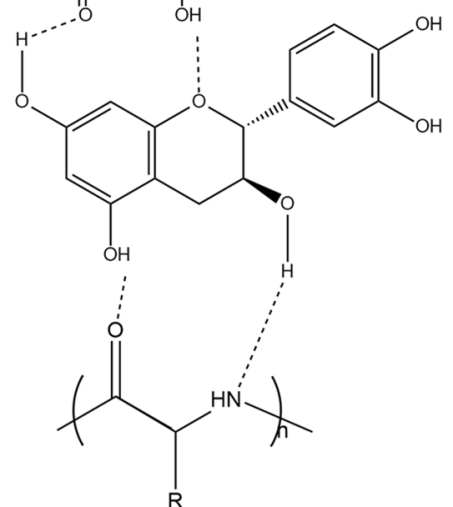

C

Fig. 7 Protein dyeing: a protein based fibres structure [190], b protein-metallic mordant-quinone dyeing mechanism [98], c wool-biomordantdye interaction mechanism [208] 
protonated in an acidic medium to form a cation that will support ionic dyeing. The presence of a carbonyl oxygen atom and the swelling of fibre due to the polar nature of the amide groups allow hydrogen bonding and dye diffusion into the fibre [208]. These fibres, and especially nylon 66 and nylon 6 , are crystalline, cationic in acidic medium and possess hydrophilic properties. Recently, both electrostatic and non-electrostatic reactions have been proposed for the colouration of nylon fibres with quinone dyes [216]. Dyeing was hypothesized to occur due to higher numbers of electrostatic and non-electrostatic interactions between the quinone dye cochineal and polyamide at $\mathrm{pH} 3$, whereas at $\mathrm{pH} 6$, the predominant reactions are the electrostatic hydrophobic interactions between the dye and fiber molecules [216]. Another report showed similar result [217]. Other tests indicate that juglone and lawsone exhibit very high affinities for hydrophobic nylon fibres at high temperatures. Some evidence of dye aggregation was noted in the solution as well as inside the fibre. Purpurin, a non-ionic hydrophobic dye, was found to colour nylon better at $70{ }^{\circ} \mathrm{C}$ [217].

Another important synthetic polymer is polyester. Here, the fibre-dye bonding mechanism is influenced by the fibre properties, such as high crystallinity, hydrophobicity, glass transition temperature $\left(\mathrm{T}_{\mathrm{g}}\right)$ and the ester linkages that makes it slightly polar. Due to its dense structure, the polyester fibre is frequently dyed at high temperatures up to $140{ }^{\circ} \mathrm{C}$, certainly beyond its $\mathrm{T}_{\mathrm{g}}$, (which lies around $80-90{ }^{\circ} \mathrm{C}$ ). This high temperature, in combination with an elevated pressure, opens up the pores of the polyester polymer and allows dye molecules to diffuse into the fibre [208, 209]. Under these dyeing conditions, natural quinones are still stable, thus making colouration possible.

\section{Cosmetics, Food and Pharmaceutical Quinone Colouration}

For centuries, quinones have been used in Arabic countries and India for cosmetic purposes to dye skin, nails and hair. The main colourant for cosmetic application is $L$. inermis (2-hydroxy-1,4-naphthoquinone), which can be found in henna [218]. The henna powder is mixed with water to form a paste and then applied to hair, nails or skin and left to dye at room temperature for about 30-40 min [218]. The dye binds to the keratin protein of the skin and securely stains the skin from pale orange to brown-black, depending on the skin type [80, 219]. Like protein textile dyeing, a mordant such as copper sulphate, is sometimes added to improve colour fastness or modify the final dye colour [219]. Juglone has also been studied as a potential cosmetic dye. Ferrous sulphate, tea, coffee, pomegranate rind, sumac extracts, oxalic acid, lactic acid, ethylenediaminetetraaceticacid (EDTA), alum and copper sulphate have been used as mordants. The dark-brown colour of hair samples obtained with the use of ferrous sulphate exhibited appropriate colour strength (18), good washing resistance (4.5 after 15 number of washes) and good resistance to sunlight (4.5, after $72 \mathrm{~h}$ of sunlight) while maintaining its original morphology [220]. The same application procedure has also been used successfully with quinones to colour hides and skins and in histological staining $[8,220]$

In the food and pharmaceuticals industry, quinones are used as food and medicine colourant in either liquid or solid state for various reasons, such as improving the product's natural colour, restoring and standardising the colour and appearance of food and medicine lost during processing or cooking, and to add a novel sensory attraction [25]. In Japan, for example, anthraquinone extracts from madder root are used as colourants for confectionery, boiled fish and soft drinks [73, 221]. These quinones are not allowed as a food additives in either the US or the EU. However, a natural red colourant anthraquinone, cochineal (additive E-120), with approximately $20 \%$ carminic acid content, is widely used as colouring agent in food processes in the EU (at dosage levels $\leq 500 \mathrm{mg} / \mathrm{kg}$ ) and in the US (only up to $5 \mathrm{mg} / \mathrm{kg}$ ) [73]. The advantage of this quinone food colourant over some synthetic colourants and even natural anthocyanins is its stability to chemical oxidation, light and oxygen. However, it is insoluble in low $\mathrm{pH}(>4)$. Furthermore, as in the case of textile dyeing, for achieving a wide range of colors, carminic acid colourant comes in a metal form which acts like mordant [33]. Carminic acid dye is also used to colour drugs with the same results as in food colouration [221].

\section{Other Functional Features of Natural Quinones}

Quinone dyes have found other industrial uses apart from colouration. They are used in solar energy harvesting, as natural alizarin and lawsone quinone dyes can improve the efficiency of dye-sensitized solar cells to increase the photovoltaic properties [222]. When a quinone-dyed cell was exposed to sunlight, it showed a shift in absorbance towards a longer wavelength, resulting in to a significant increase in the short circuit current density and conversion efficiency. When hydroquinone and benzoquinone dye were used as a redox couple in a solar cell, the conversion efficiency of the cell improved from $4.7 \%$ using the conventional method to $5.2 \%$ [223].

An extract from Oldenlandia umbellata, commonly known as Indian madder, has been recommended for use as a pH indicator since it changes colour depending on the $\mathrm{pH}$, i.e. it is yellow at $\mathrm{pH} 4.8-5.1$, red at $\mathrm{pH}$ above 10 and green at an acidic $\mathrm{pH}$ below 3 . The dye can be used to colour paper strips for use as a $\mathrm{pH}$ indicator strips or sensorial materials.

Other application areas where natural quinone dyes have been used are corrosion prevention on metal surfaces [84] 
and as pigments for ink for felt tip pens, ball pens, stamp pads and jet printing ink [224, 225].

\section{Conclusion}

This review has covered natural quinones as a dyeing compound. The main areas considered are quinone structure, occurrence, biogenesis, toxicology, isolation, purification, chemical analysis and applications with respect to textile colouration. Quinones are shown to have varied structures, with many substitution sites, and this structure gives rise to wide range of colours. The review also reveals that, for the three classes of quinones, over 700 sources of anthraquinones, over120 sources of naphthoquinones and a limited number of benzoquinones are known globally. The quinones are ubiquitous, though at limited concentrations. The main source is flowering plants, which accounts for more than half of the total currently in use, meaning that these sources are fully sustainable.

The paper also reviews the techniques for quinone isolation, identification, and quantification. As predicted by the Hansen solubility theory, solvent extraction using higher polarity solvents, like methanol, methanol-water, ethanol, ethanol-water, or water, is the recommended method for anthraquinones and naphthoquinones isolation and provides shorter extraction time at high temperatures (90-98) ${ }^{\circ} \mathrm{C}$ or at temperatures below the boiling points of solvents. For benzoquinones, lower polarity solvents, such as ethyl acetate and butanol, are recommended. Conventional extraction methods, such as reflux and maceration, are the preferred isolation techniques. Apart from classical methods, other techniques, like sonication, microwave assisted, sublimation, supercritical fluid, enzymatic and pressurised fluid extraction are also frequently used due to their speed, efficiency, selectivity and environmental friendliness. For a quick check of quinone compound occurrence in a plant extract, Bornträger's test stands out as a the preferred method for anthraquinones, while the acid reaction is useful for testing for the presence of naphthoquinones and benzoquinones. Additionally, HPLC seems to be the dominant method for purification due to its high separation quality, speed and reproducibility. For detailed analytical characterisation of quinones, UV, DAD and MS detectors are the most common, due to their ease of use and relatively low cost. For quantitative analysis of natural quinone extracts, UV-Vis spectrophotometry is a more popular analytical technique due to its simplicity, speed and ability to detect or determine purified or unpurified quinone samples with LOQ in the order of picograms. For accuracy in analysis for in-depth structure elucidation, MS is preferred.
The paper also revealed that natural quinone dyes can be used to dye both natural and synthetic textiles through the simple classical exhaustion method or through padding technique. Also, dyeing can be exhausted into the fiber after vatting the dye. These methods yield almost all colour shades. Additionally, satisfactory results have been achieved with or without the use of mordants. Moreover, compared to other colourants, they also impart special finishing properties to textiles, including, antibacterial, antifungal, anti-insect and UV protection features. Cosmetics, food and pharmaceuticals are also being coloured by natural quinones. Compared with their synthetic counterparts, natural quinones are potentially more sustainable, comparatively safer and easily biodegradable. These features mean that they can be removed fast and efficiently by a less costly wastewater treatment systems, making them comparatively safer for the environment. Based on all these points, we conclude that the interest in natural quinone dyes will continue to increase, as will their market penetration rate, as such replacing their synthetic equivalents.

Supplementary Information The online version contains supplementary material available at https://doi.org/10.1007/s12649-021-01443-9.

Acknowledgements The authors hereby acknowledge that this research work has been conducted within the framework of the TEAM project 'Towards a more integrated management of organic waste in Kenya; the production of natural dyes from fruit and vegetable waste', Project No. KE2018TEA464A103 with financial support from the VLIR-UOS, Belgium.

Authors Contributions BD: investigation, writing- original draft preparation; KP: conceptualisation, writing- reviewing and editing. JG: supervision, conceptualisation, writing- reviewing and editing, sourcing for funds, resources: KR: conceptualisation, writing- reviewing and editing. SM: supervision, conceptualisation, writing- reviewing and editing, funding acquisition, resources.

\section{Declarations}

Conflict of interest The authors declare that they have no known competing financial interests or personal relationships that could have appeared to influence the work reported in this paper.

Open Access This article is licensed under a Creative Commons Attribution 4.0 International License, which permits use, sharing, adaptation, distribution and reproduction in any medium or format, as long as you give appropriate credit to the original author(s) and the source, provide a link to the Creative Commons licence, and indicate if changes were made. The images or other third party material in this article are included in the article's Creative Commons licence, unless indicated otherwise in a credit line to the material. If material is not included in the article's Creative Commons licence and your intended use is not permitted by statutory regulation or exceeds the permitted use, you will need to obtain permission directly from the copyright holder. To view a copy of this licence, visit http://creativecommons.org/licenses/by/4.0/. 


\section{References}

1. Choi, S.Z., Lee, S.O., Jang, K.U., Chung, S.H., Park, S.H., Kang, H.C., Yang, E.Y., Cho, H.J., Lee, K.R.: Antidiabetic stilbene and anthraquinone derivatives from Rheum undulatum. Arch. Pharm. Res. 28(9), 1027-1030 (2005). https://doi.org/ 10.1007/bf02977396

2. Rao, C.R., Wasif, A.I., Patil, P.: Natural dyes making their way back to a golden age. Text. Asia 43, 28-31 (2012)

3. Gulrajani, M.L.: Present status of natural dyes. Indian J. Fibre Text. Res. 26, 191-201 (2001)

4. Patil, P., D., Rao C, R., Wasif A, I.: Revival of natural dyes: smart use of biotechnology. Colourage 10, Magazine Communications, 33-38 (2012).

5. Yusuf, M., Shabbir, M., Mohammad, F.: Natural colourants: historical, processing and sustainable prospects. Nat. Prod. Bioprospect. 7, 123-145 (2017)

6. Ado, A., Yahaya, H., Kwalli, A.A., Abdulkadir, R.S.: Dyeing of textiles with eco-friendly natural dyes: a review. Int. J. Environ. Monit. Prot. 1(5), 76-82 (2014)

7. Samanta, A., Agarwal, P.: Application of natural dyes on textiles. Indian J Fibre Text Res 34, 384-399 (2009)

8. Kiernan, J.A.: Classification and naming of dyes, stains, and fluorochromes. Biotech. Histochem. 76, 261-277 (2001)

9. Riikka, R.: Anthraquinones from the fungus Dermocybe sanguinea as textile dyes, pp. 1-107. University of Helsinski, Helsinski (2002)

10. Samanta, A., Konar, A.: Dyeing of textiles with natural dyes. InTech, Fontana (2011)

11. Sinha, A.K., Kumar, J.K.: Resurgance of natural colourants: a holistic view. Nat. Prod. Lett. 18(1), 59-84 (2004)

12. Bruna de Campos, V.-C., Marin-Morales, M.A.: Azo dyes: characterization and toxicity-a review. Text. Light Ind. Sci. Technol. (TLIST) 2(2), 85-103 (2013)

13. Novotný, Č, Dias, N., Kapanen, A., Malachová, K., Vándrovcová, M., Itävaara, M., Lima, N.: Comparative use of bacterial, algal and protozoan tests to study toxicity of azo- and anthraquinone dyes. Chemosphere 63(9), 1436-1442 (2006). https://doi.org/10.1016/j.chemosphere.2005.10.002

14. Enviromental Control, I.: Anthraquinone dye toxicological profiles, vol. 198312. Consumer Product Safety Commission, Rockville (1981)

15. Patel, B.H.: Handbook of textile and industrial dyeing: principles, processes and types of dyes, vol. 1. Woodhead Publishing, Cambridge (2011)

16. Kiokias, S., Proestos, C., Varzakas, T.: A review of the structure, biosynthesis, absorption of carotenoids-analysis and properties of their common natural extracts. Curr. Res. Nut. Food Sci. (2016). https://doi.org/10.12944/CRNFSJ.4.Speci al-Issue 1.03

17. Héctor, A.-E., Iram, M.-F., Pablo, G.-M., Jaime, L.-C., Roberto, R.-R.: Carotenoids extraction and quantification: a review. Anal. Methods 2013(5), 2916-2924 (2013)

18. Rodriguez-Amaya, D.B.: Update on natural food pigments-a mini-review on carotenoids, anthocyanins, and betalains. Food Res. Int. 124, 200-205 (2019)

19. Ozan, D., Recep, K.: A review on the flavonoids-a dye source. Int. J. Adv. Eng. Pure Sci. 3, 188-120 (2019). https://doi.org/ 10.7240/jeps.476514

20. Thomson, R.: Naturally occurring quinones. Academic Press 1, London (1971)

21. Abaham, I., Joshi, R., Pardasani, P., Pardasani, R.: T: Recent advances in 1,4-benzoquinone chemistry. J. Braz. Chem. Soc. 22(3), 385-421 (2011)
22. Dandawate, P.R., Vyas, A.C., Padhye, S.B., Sing, M.W., Baruah, J.B.: Perspectives on medicinal properties of benzoquinone compounds. Mini-Rev. Med. Chem. 10(5), 436-454 (2010)

23. Kumagai, Y., Shinkai, Y., Miura, T., Cho, A.K.: The chemical biology of naphthoquinones and its environmental implications. Ann. Rev. Pharmacol. Toxicol. 52, 221-247 (2012)

24. Lopez Lopez, L.I., Nery Flores, S.D., Silva Belmares, S.Y., Saenz Galindo, A.: Napththoquinones: biological properties and synthesis of lawsone and derivatives - a structured review. Vitae 21, 248-258 (2014)

25. Caro, Y., Anamale, L., Fouilland, M., Laurent, P., Petit, T., Duffose, L.: Natural hydroxyanthraquinoid pigments as potent food grade coloUrants: an overview. Nat. Prod. Bioprospect. 2, 174-194 (2012)

26. Duval, J., Pecher, V., Paujal, M., Lessellier, E.: Research advances for extraction, analysis and uses of anthroquinones: a review. Ind. Crops Prod. 94, 812-833 (2016)

27. Borges, M.E., Tejera, R.L., Díaz, L., Esparza, P., Ibáñez, E.: Natural dyes extraction from cochineal (Dactylopius coccus). New extraction methods. Food Chem. 132(4), 1855-1860 (2012). https://doi.org/10.1016/j.foodchem.2011.12.018

28. Seyhan, S.A., Demirbağ, C., Dölen, E.: Identification of the main dyestuffs obtained from Kermes (Kermes vermilio) in the Northwest of Turkey. Ann. Chem. 30(1), 1-4 (2019). https://doi.org/ 10.2478/auoc-2019-0001

29. Zakaria, R.M., Nizam, E.H., Al Mamun, H., Yousuf, A., Ali, R., Rahman, L., Miah, R.: Dyeing of S/J cotton knit fabric with natural dye extracts from green walnut shells: assessment of mordanting effect on fastness properties. J. Text. Sci. Technol. 3, 17-30 (2017)

30. Izhaki, I.: Emodin: a secondary metabolite with multiple ecological functions in higher plants. New Phytol. 155(2), 205-207 (2002)

31. Leistner, E.: Biosynthesis of plants quinones. In: Biochemistry of plants, vol. 3, pp. 403-420. Academic Press inc., Bonn (1981)

32. Harborne, J.B.: Phytochemical methods: a guide to modern techniques of plant nalysis. Chapman and Hall, New York (1998)

33. Derksen, G.C.H.: Red, red, madder: Analysis and isolation of anthraquinones from madder roots (Rubia tinctorum). In: Dessertation. Wageningen Universiteit. (2001)

34. Ning, W., Su, M., Liang, S., Sun, H.: Investigation of six bioactive anthraquinones in slimming tea by accelerated solvent extraction and high performance capillary electrophoresis with diode-array detection. Food Chem. 199, 1-7 (2016)

35. Conn, P.K., Stumpf, E.E.: Secondary plant products. In: The biochemistry of plants, vol. 7, pp. 403-420. Academic Press, Bonn (1981)

36. De Santis, D., Moresi, M.: Production of alizarin extracts from Rubia tinctorum and assessment of their dyeing properties. Ind. Crops Prod. 26, 151-162 (2007)

37. Chemchame, Y., Mohanmed, E.M., Anass, M.: Dyeing wool fiber with natural alizarin in a Vat system. Am. J. Appl. Chem. 4(5), 170-173 (2016)

38. Aditya, A.U., Pereira, G.R., Laddha, K.S.: Assessment of conventional and novel extraction techniqueson extraction efficiency of five anthraquinones from Rheum emodi. J. Food Sci. Technol. 52, 6574-6582 (2015)

39. Dave, H., Ledwani, L.: A review on anthraquinones isolated from Cassia species and their applications. Indian J. Nat. Prod. Resour. 3(3), 291-319 (2012)

40. Kang, J., Zhang, P., Gao, Z., Zhang, J., Yan, Z., Wang, H.: Naphthohydroquinones, naphthoquinones, anthraquinones, and a naphthohydroqinone dimer isolated from the aerial parts of Marinda parvifolia and their cytotoxic effects through up-reulation p53. Phytochemistry 130, 144-151 (2016) 
41. Kosikowska, U., Smolarz, H.D., Malm, A.: Antimicrobial activity and total content of polyphenols of Rheum L. species growing in Poland. Cent. Eur. J. Biol. 5(6), 814-820 (2010)

42. Bhuyan, R., Saikia, C.N.: Isolation of colour components from native dye-bearing plants in northeastern India. Biores. Technol. 96(3), 363-372 (2005). https://doi.org/10.1016/j.biortech.2004. 02.032

43. Qui, H.-Y., Wang, P.-F., Lin, H.-Y., Tang, C.-Y.: Naphthoquinones: a continuing source for discovery of therapeutic antineoplastic agents. Chem. Biol. Drug Des. (2017). https://doi.org/10. 1111/cbdd.13141

44. Bukhari, M., Salam, S., Shabbir, M., Jameel, L., Shahid, M., Singh, U., Khan, M., Mohammad, F.: Dyeing studies and fastness properties of brown naphtoquinone colourant extracted from Juglans regia L on natural protein fibre using different metal salt mordants. Text. Cloth. Sustain. (2017). https://doi.org/10.1186/ s40689-016-0025-2

45. Basant, T., Jahan, S.: Process development of silk dyeing with natural dye extracted from plumbago zeylanica roots. Man-Made Text. India 42(4), 137-139 (2014)

46. Sarang, H., Rajani, P., Vasanthakumari, M.M., Kumara, P.M., Siva, R., Ravikanth, G., Shanker, R.U.: An endophytic fungus, Gibberella moniliformis from Lawsonia inermis L. produces lawsone, an orange-red pigment. Antonie Leeuwenhoek 110, 853-862 (2017)

47. Sharma, K., Pareek, P.K., Aam, R., Temani, P.: Extraction of natural dye from Kigelia pinnata and its application on pashmina (cashmere) fabric. Res. J. Text. Appar. 17(2), 28-32 (2013)

48. Riza, A., Elcin, G.: The use of nutshell firstly as a natural dye for cotton and wool and then as a natural adsorbent for colour removal of basic dye effluent. Colour Technol. 133, 88-89 (2016)

49. Gupta, K.C., Gupta, P., Singh, P., Singh, S.V., Agarwal, S.: Chemistry of natural dyes. In: Danie, M., Bhattacharya, S.D., Arya, A., Raole, V.D. (eds.) Natural dyes: scope and challenges, pp. 7-34. Scientific publisher, Baroda (2006)

50. Joshi, B.A., Jadhav, A.A.: Extraction and quantitative estimation of bio active component (yellow and red carthamin) from dried safflower petals. Indian J. Sci. Technol. (2015). https://doi.org/ 10.17485/ijst/2015/v8i16/42380

51. Espinoza-Hernández, T.C., Rodríguez-Herrera, R., AguilarGonzález, C.N., Lara-Victoriano, F., Reyes-Valdés, M.H., Castillo-Reyes, F.: Characterization of three novel pigment-producing Penicillium strains isolated from the Mexican semi-desert. Afr. J. Biotechnol. 12(22), 3405-3413 (2013)

52. Basnet, B.B., Liu, L., Zhao, W., Liu, R., Ma, K., Bao, L., Ren, J., Wei, X., Yu, H., Wei, J., Liu, H.: New 1, 2-naphthoquinonederived pigments from the mycobiont of lichen Trypethelium eluteriae Sprengel. Nat. Prod. Res. 33(14), 2044-2050 (2019). https://doi.org/10.1080/14786419.2018.1484458

53. Pedrini, N., Ortiz-Urquiza, A., Huarte-Bonnet, C., Fan, Y., Juárez, M.P., Keyhani, N.: Tenebrionid secretions and a fungal benzoquinone oxidoreductase form competing components of an arms race between a host and pathogen. Proc. Natl. Acad. Sci. U.S.A. 112, 8519-8520 (2015). https://doi.org/10.1073/pnas. 1504552112

54. Gessler, N., Egorova, A., Belozerskaya, T.: Fungal anthraquinones. Appl. Biochem. Microbiol. 49(2), 85-99 (2013)

55. Akilandeswari, P., Pradeep, B.V.: Exploration of industrially important pigments from soil fungi. Appl. Microbiol. Biotechnol. 100(4), 1631-1643 (2016). https://doi.org/10.1007/ s00253-015-7231-8

56. Balachandran, C., Duraipandiyan, V., Arun, Y., Sangeetha, B., Emi, N., Al-Dhabi, N.A., Ignacimuthu, S., Inaguma, Y., Okamoto, A., Perumal, P.T.: Isolation and characterization of 2-hydroxy-9,10-anthraquinone from Streptomyces olivochromogenes (ERINLG-261) with antimicrobial and antiproliferative properties. Rev. Bras. Farmacogn. 26, 285295 (2016)

57. Shen, X., Wang, X., Huang, T., Deng, Z., Lin, S.: Naphthoquinone-based meroterpenoids from marine-derived Streptomyces sp. B9173. Biomolecules 10(8), 1187 (2020)

58. Ge, F., Xiao, Y., Yang, Y., Wang, W., Moe, B., Li, X.-F.: Formation of water disinfection byproduct 2,6-dichloro-1,4-benzoquinone from chlorination of green algae. J. Environ. Sci. 63, 1-8 (2018). https://doi.org/10.1016/j.jes.2017.10.001

59. Perry, N.B., Blunt, J.W., Munro, M.H.G.: A cytotoxic and antifungal 1,4-naphthoquinone and related compounds from a New Zealand brown alga, Landsburgia quercifolia. J. Nat. Prod. 54(4), 978-985 (1991). https://doi.org/10.1021/np50076a009

60. Vinay, P., Ashawat, M.S., Verma, C.P.S.: Pattern of anthraquinone derivatives in some Cassia species: qualitative and quantitative estimantion. World J. Pharm. Pharm. Sci. 5(11), 1067-1096 (2016)

61. Gritsanapan, W., Aurapa, S.: Determination of anthroquinone glycoside content in Cassia fistula leaf extract for alternative source of luxative drug. Indian J. Pharm. Sci. 3(1), 42-45 (2009)

62. Hagendoorn, M.J.M., Van der Plas, L.H.W., Segers, G.: J: Accumulation of anthraquinones in Morinda citrifolia cell suspensions. Plant Cell Tissue Organ. Cult. 38, 227-234 (1994). https://doi.org/10.1007/BF00033881

63. Mischenko, N.P., Zhuravlev, Y.N.: Anthraquinone production by callus cultures of Rubia cordifolia. Fitoterapia 70(6), 552-557 (1999)

64. Ramamoorthy, S., Mudgal, G., Rajesh, D., Nawaz Khan, F., Vijayakumar, V., Rajasekaran, C.: Characterisation of novel $\mathrm{pH}$ indicator of natural dye Oldenlandia umbellata L. Nat. Prod. Res. 23, 1210-1216 (2009)

65. Goncalves, R., Leitesilva, E., Hioka, N., Nakamura, C., Bruschi, M., Caetano, W.: An optimized protocol for anthraquinones isolation from Rhamnus frangula $\mathrm{L}$. Nat. Prod. Res. (2017). https://doi.org/10.1080/14786419.2017.1356836

66. Angelini, L.G., Pistelli, L., Belloni, P., Bertoli, A., Penconesi, S.: Rubia tictorum a source of natural dyes: agronomic evaluation, quantitative analysys of alizarin and industrial assays. Ind. Crops Prod. 6, 303-311 (1997)

67. Dufossé, L.: Microbial production of food grade pigments. Food Technol. Biotechnol. 44(3), 313-323 (2006)

68. Boonyapranai, K., Tungpradit, R., Lhieochaiphant, S., Phutrakul, S.: Optimization of submerged culture for the production of naphthoquinones pigment by Fusarium verticillioides. Chiang Mai J. Sci 35(3), 457-466 (2008)

69. Tappeiner, J., Vasiliou, A., Ganzera, M., Fessas, D., Stuppner, H., Papageorgiou, V.P., Assimopoulou, A., N, : Quantitative determination of alkannins and shikonins in endemic mediterranean Alkanna species. Biomed. Chromatogr. 28(7), 923-933 (2014). https://doi.org/10.1002/bmc.3096

70. Almeida, P., Borrego, L., Melián, E., González Díaz, O.: Quantification of p-phenylenediamine and 2-hydroxy-1,4-naphthoquinone in henna tattoos. Contact Dermat. 66, 33-37 (2012). https://doi.org/10.1111/j.1600-0536.2011.01992.x

71. Lobstein, A., Brenne, X., Feist, E., Metz, N., Weniger, B., Anton, R.: Quantitative determination of naphthoquinones of impatiens species. Phytochem. Anal. 12, 202-205 (2001)

72. Ozgen, U., Miloglu, F.D., Bulut, G.: Quantitative determination of shikonin derivatives with UV-Vis spectrophotometric methods in the roots of Onosma nigricaule. Rev. Anal. Chem. 30(2), 59 (2011)

73. Mussak, R., Thomas, B.: Handbook of natural colourants. Wiley, Chichester (2009) 
74. Jan, K., Andrija, S., Thomas, B., Thomas, B.: The hyp-1 gene is not a limiting factor for hypericin biosynthesis in the genus Hypericum. Funct. Plant Biol. 38, 35-43 (2011)

75. Venil, C.K., Velmurugan, P., Dufossé, L., Renuka Devi, P., Veera Ravi, A.: Fungal pigments: potential coloring compounds for wide ranging applications in textile dyeing. J. Fungi 6(2), 68 (2020)

76. Namdeo, A.: Plant cell elicitation for production of secondary metabolites: a review. Pharmacogn. Rev 1(1), 69-79 (2007)

77. Jin, J.H., Shin, J.H., Kim, J.H., Chung, I.S., Lee, H.J.: Effect of chitosan elicitation and media components on the production of anthraquinone colorants in madder (Rubia akane Nakai) cell culture. Biotechnol. Bioproc. Eng. 4(4), 300 (1999)

78. Hussain, M.S., Fareed, S., Ansari, S., Rahman, M.A., Ahmad, I.Z., Saeed, M.: Current approaches toward production of secondary plant metabolites. J. Pharm. Bioallied Sci. 4(1), 10-20 (2012). https://doi.org/10.4103/0975-7406.92725

79. Kulkarni, S.: Physico-chemical, Biological properties, and applications of quinone, its derivatives - a review. Asian J. Res. Chem. 11(1), 72-74 (2018)

80. Dhananjay, K., Singha, D.K., Suaib, L.S., Ajay, K., Mathur, A.K.: Lawsonia inermis L.- a commercially important primaeval dying and medicinal plant with diverse pharmacological activity: a review. Ind. Crops Prod. 65, 269-286 (2015)

81. Srivastava, S., Chowdhury, R.A., Maurya, S.: Antimicrobial efficacy of methylated lac dye, an anthraquinone derivative. Indian J. Microbiol. 15(4), 470-476 (2017)

82. Samanta, A.K., Konar, A.: Dyeing of textiles with natural dyes. In: Perrin, E., Kumbasar, A. (eds.) Natural dyes, pp. 30-56. Fontana, InTech (2011)

83. Park, J.H., Gatewood, B.M., Ramaswamy, G.N.: Naturally occurring quinones and flavonoid dyes for wool: insect feeding deterrents. J. Appl. Polym. Sci 98, 322-328 (2005)

84. Dananjaya, S.H.S., Edussuriya, M., Dissanayake, A.S.: Inhibition action of lawsome on the corrosion of mild steel. Online J. Sci. Technol. 2(2), 32-36 (2012)

85. Son, E.J., Kim, J.H., Kim, K., Park, C.B.: Quinone and its derivatives for energy harvesting and storage materials. J. Mater. Chem. A 4, 11179-11202 (2016)

86. Li, F., Li, X., Shao, J., Chi, P., Chen, J., Wang, Z.: Estrogenic activity of anthraquinone derivatives: in vitro and in silico studies. Chem. Res. Toxicol. 23, 1349-1355 (2010). https://doi.org/ $10.1021 / \mathrm{tx} 100118 \mathrm{~g}$

87. Zheng, Z., Dutton, P.L., Gunner, M.R.: The measured and calculated affinity of methyl- and methoxy-substituted benzoquinones for the Q(A) site of bacterial reaction centers. Proteins 78(12), 2638-2654 (2010). https://doi.org/10.1002/prot.22779

88. Islam, R., Mamat, Y., Ismayil, I., Yan, M., Kadir, M., Abdugheny, A., Rapkat, H., Niyaz, M., Ali, Y., Abay, S.: Toxicity of anthraquinones: differential effects of rumex seed extracts on rat organ weights and biochemical and haematological parameters. Phytother. Res. 29(5), 777-784 (2015). https://doi.org/10.1002/ ptr.5317

89. Shukla, V., Asthana, S., Gupta, P., Dwivedi, P., Tripathi, A., Das, M.: Toxicity of naturally occurring anthraquinones, pp. 1-50. Elsevier, Amsterdam (2017)

90. Saxena, S., Raja, A.S.M.: Natural dyes: sources, chemistry, application and sustainability Iissues. In: Muthu, S.S. (ed.) Roadmap to sustainable textiles and clothing: eco-friendly raw materials, technologies, and processing methods, pp. 37-80. Springer, Singapore (2014)

91. Wright, D.A., Mitchelmore, C.L., Dawson, R., Cutler, H.G.: The influence of water quality on the toxicity and degradation of juglone (5-Hydroxy 1,4-Naphthoquinone). Environ. Technol. 28(10), 1091-1101 (2007). https://doi.org/10.1080/0959333280 8618873
92. Carmen, Z., Daniela, S.: Textile organic dyes-characteristics, polluting effects and separation/elimination procedures from industrial effluents - a critical overview. In: Puzyn, T., Mostrag, A. (eds.) Organic pollutants ten years after the stockholm convention-environmental and analytical update. InTech, London (2012)

93. Environmental, Protection, Agency: Anthraquinone (122701) Fact sheet. In. Office of pesticide programs, 1200 Pennsylvania Avenue, NW, Washington, D.C. 20460, pp. 1-7 (1998)

94. Commission, E.: Public consultation on the proposed ban on the use of 49 cosmetic substances in hair dye products. In: Directorate-general enterprise and industry unit F/3, C.a.M.D. (ed.). Brussels, Belgium, pp. 1-7 (2007)

95. Kirkland, D., Marzin, D.: An assessment of the genotoxicity of 2-hydroxy-1,4-naphthoquinone, the natural dye ingredient of Henna. Mutat. Res. 537, 183-199 (2003). https://doi.org/10. 1016/S1383-5718(03)00077-9

96. Kumar, G.S., Jayaveera, K.N., Kumar, C.K., Sanjay, U.P., Swamy, B.M., Kumar, D.V.: Antimicrobial effects of Indian medicinal plants against acne-inducing bacteria. Trop. J. Pharm. Res. 6(2), 717-723 (2007)

97. Bhuiyan, M.A.R., Islam, A., Islam, S., Hossain, A., Nahar, K.: Improving dyeability and antibacterialactivity of Lawsonia inermis L. on jute fabrics by chitosan pretreatment. Text. Cloth Technol. (2017). https://doi.org/10.1186/s40689-016-0023-4

98. Yusuf, M., Ahmad, A., Shahid, M., Khan, M.: Assessment of colourimetric, antibacterial and antifungal properties of woollen yarn dyed with the extract of the leaves of henna (Lawsonia inermis). J. Clean. Prod. 27, 42-50 (2012)

99. Alebeid, O.K., Tao, Z., Seedahmed, A.: New approach for dyeing and UV protection properties of cotton fabric using natural dye extracted from henna leave. Fibres Text. East. Eur. 3(113), 60-65 (2015)

100. Dhandapani, S.R., Sankar, A.K.: Antibacterial activity and UV property of shikonin on silk substrate. J. Text. Appar. Technol. Manage. 5(4), 1-7 (2007)

101. Srinivas, K., King, J.W., Monrad, J.K., Howard, L.R., Hansen, C.M.: Optimization of subcritical fluid extraction of bioactive compounds using Hansen solubility parameters. J Food Sci 74(6), E342-354 (2009). https://doi.org/10.1111/j.1750-3841. 2009.01251.x

102. Salman, R.K., Salih, J.M.: A new approach to estimate Hansen solubility using maple software. Int. J. Appl. Eng. Res. 12(15), 4858-4863 (2017)

103. Hansena, C.M., Smith, A.L.: Using Hansen solubility parameters to correlate solubilityof C60fullerene in organic solvents and in polymers. Carbon 42, 1591-1597 (2007). https://doi.org/ 10.1016/j.carbon.2004.02.011

104. Zhe, W., Pei, M., Lijia, X., Chunnian, H., Yong, P., Peigen, X.: Evaluation of the content variation of anthraquinone glycosides in rhubarb by UPLC-PDA. Chem. Cent. J. (2013). https://doi.org/ 10.1186/1752-153X-7-170

105. Bhuyan, R., Saikia, C.N.: Extraction of natural colourants from of Marinda angustifolia Roxb.: their identification and studies of dyeing characteristics on wool. Indian J. Chem. Technol. 10, 131-136 (2003)

106. Junko, K., Izumi, M., Norihiro, K.: Simultaneous determination of anthraquinones in rhubarb by high-performance liquid chromatography and capillary electrophoresis. J. Chromatogr. A 1145(1-2), 183-189 (2007)

107. Sharma, N., Ghosh, P., Sharma, U.K., Sood, S., Sinha, A.K., Gulati, A.: Microwave-assisted efficient extraction and stability of juglone in different solvents from Juglans regia: quantification of six phenolic constituents by Validated RP-HPLC and evaluation of antimicrobial activity. Anal. Lett. 42(16), 2592-2609 (2009). https://doi.org/10.1080/00032710903202055 
108. Mahesh, G., Melvin, M., Aruna, S., Prithvi, S.: Influence of microwave and ultrasound pretreatment on solvent extraction of bio-components from walnut (Julgans regia L.) shell. Period. Polytech. Chem. Eng. 60(1), 40-48 (2016)

109. Wirod, M., Pharkphoom, P.: Quantitative HPLC analysis and extraction of 2,6-dimethoxy-1,4-benzoquinone from Ficus foveolata stems. Nat. Prod. Sci. 21(3), 192-195 (2015)

110. Feng, Z., Sujuan, W., Sheng, L., Chenggen, Z., Zhenggang, Y., Yang, Y., Bo, L., Xiuli, W., Yongchun, Y., Yan, L., Jiangong, S.: Natural and unnatural anthraquinones isolated from the ethanol extract of the roots of Knoxia valerianoides. Acta Pharm. Sin. 2(3), 260-266 (2012). https://doi.org/10.1016/j.apsb.2012.03.004

111. Ford, L.L: Chemical analysis and elucidation of anthraquinone and flavonoid type compounds with applications to historical artefactsand sustainability. Ph. D. thesis. The University of Leeds, (2017)

112. Ford, L., Rayner, C.M., Blackburn, R.S.: Isolation and extraction of ruberythric acid from Rubia tinctorum L. and crystal structure elucidation. Thytochemistry 117, 168-173 (2015)

113. Krizsan, K., Szokan, G.E., Toth, Z.A., Hollosy, F., Laszlo, M., Khlafulla, A.: HPLC analysis of anthraquinone derivatives in madder root (Rubia tinctorum) and its cell cultures. J. Liq. Chromatogr. Relat. Technol. 14, 2295-2314 (1996)

114. Itokawa, H., Mihara, K., Takeya, K.: Studies on a novel anthraquinone and its glycosides isolated from Rubia cordifolia and R. akane. Chem. Pharm. Bull. 31, 2353-2358 (1983)

115. Teruyuki, M., Masahito, T., Setsuji, T.: Selective solvent extraction of ruberythric acid from madder roots and subsequent hydrolysis with $\beta$-glucosidase. J. Ferment. Bioeng. 81(6), 567569 (1996)

116. Shang, X.-F., Zhao, Z.-M., Li, J.-C., Yang, G.-Z., Liu, Y.-Q., Dai, L.-X., Zhang, Z.-J., Yang, Z.-G., Miao, X.-L., Yang, C.-J., Zhang, J.-Y.: Insecticidal and antifungal activities of Rheum palmatum L. anthraquinones and structurally related compounds. Ind. Crops Prod. 137, 508-520 (2019). https://doi.org/10.1016/j. indcrop.2019.05.055

117. Kang, J., Zhang, P., Gao, Z., Zhang, J., Yan, Z., Wang, H., Chen, R.: Naphthohydroquinones, naphthoquinones, anthraquinones, and a naphthohydroquinone dimer isolated from the aerial parts of Morinda parvifolia and their cytotoxic effects through upregulation of p53. Phytochemistry 130, 144-151 (2016). https:// doi.org/10.1016/j.phytochem.2016.04.001

118. Vázquez, M.F.B., Comini, L., Martini, R.E., Montoya, S.N.N., Bottini, S., Cabrera, J.: Comparisons between conventional, ultrasound-assisted and microwave-assisted methods for extraction of anthraquinones from Heterophyllaea pustulata Hook $\mathrm{f}$. (Rubiaceae). Ultrason. Sonochem. 21(2), 478-484 (2014)

119. Chen, R.-R., Liu, J., Chen, Z., Cai, W.-J., Li, X.-F., Lu, C.-L.: Anthraquinones extract from Morinda angustifolia Roxb. Root alleviates hepatic injury induced by carbon tetrachloride through Inhibition of hepatic oxidative stress. Evid. Based Complement Altern. Med. (2020). https://doi.org/10.1155/2020/9861571

120. Suktham, K., Daisuk, P., Shotipruk, A.: Microwave-assisted extraction of antioxidative anthraquinones from roots of Morinda citrifolia L. (Rubiaceae): Errata and review of technological development and prospects. Sep. Purif. Technol. 256, 117844 (2021). https://doi.org/10.1016/j.seppur.2020.117844

121. Barrera Vázquez, M.F., Andreatta, A.E., Martini, R.E., Núñez Montoya, S.C., Cabrera, J.L., Comini, L.R.: Optimization of pretreatment with microwaves prior the pressurized hot water extraction of anthraquinones from Heterophyllaea pustulata, using Doehlert experimental design. Chem. Eng. Process.- Process Intensif. 155, 108055 (2020). https://doi.org/10.1016/j.cep. 2020.108055

122. George, G., Sengupta, P., Paul, A.T.: Optimisation of an extraction conditions for Rumex nepalensis anthraquinones and its correlation with pancreatic lipase inhibitory activity. J. Food Compos. Anal. 92, 103575 (2020). https://doi.org/10.1016/j. jfca.2020.103575

123. Hosseinnezhad, M., Gharanjig, K., Jafari, R., Imani, H., Razani, $\mathrm{N}$.: Cleaner colorant extraction and environmentally wool dyeing using oak as eco-friendly mordant. Environ. Sci. Pollut. Res. (2020). https://doi.org/10.1007/s11356-020-11041-2

124. Hynninen, P., Räisänen, R., Elovaara, P., Nokelainen, E.: Preparative isolation of anthraquinones from the Fungus Dermocybe sanguined using enzymatic hydrolysis by the endogenous $\beta$-glucosidase. Z. Naturforsch. C (2000). https://doi.org/10.1515/ znc-2000-7-820

125. Zhang, G., Chi, X.: A green strategy for obtaining anthraquinones from Rheum tanguticum by subcritical water. Open Chem. 18(1), 702-710 (2020). https://doi.org/10.1515/chem-2020-0079

126. Seabra, I.J., Braga, M.E.M., Oliveira, R.A., de Sousa, H.C.: Twostep high pressure solvent extraction of walnut (Juglans regia L.) husks: $\mathrm{scCO}_{2}{ }^{+} \mathrm{CO}_{2} /$ ethanol/ $\mathrm{H}_{2} \mathrm{O}$. J. $\mathrm{CO} 2$ Util. 34, 375-385 (2019). https://doi.org/10.1016/j.jcou.2019.07.028

127. Rocio, B.-A., Andres, U.-C., Carlos, Q.-N., Gonzalo, C.-E., Mirbela, C.: Fafrin: a selective chemical method for the separation of quinones from the stem bark of Diospiros anisandra. Int. J. Curr. Pharm. Res. 5(4), 13-17 (2013)

128. Derksen, G.C.H., Harm, A.G., Nienderlander, H.A.G., van Beek, T.A.: Analysis of anthraquinones in Rubia tinctorum L. by liquid chromatography coupled with diode-array UV and mass spectrophotometric detection. J. Chromatogr. A 978, 119-127 (2002)

129. Pharkphoom, P., Apirak, S., Athip, S.: Quantitative HPLC determination and extraction of anthraquinones in Senna alata Leaves. J. Chromatogr. Sci. 4, 197-200 (2009)

130. Yan, Y., Chen, X., Hu, S., Tian, J., Bai, X.: Simultaneous preconcentration and analysis of anthraquinones based on ultrasound emulsification ionic liquid microextraction. J. Chromatogr. Sci. 52, 218-225 (2014). https://doi.org/10.1093/chromsci/bmt014

131. Nandini, S., Partha, G., Sharma, U.K., Swati, S., Sinha, K., Arvind, G.: Microwave-assisted efficient extraction and stability of juglone in different solvents from juglans regia: quantification of six phenolic constituents by validated RP-HPLC and evaluation of antimicrobial activity. Anal. Lett. 42(16), 2592-2609 (2009). https://doi.org/10.1080/00032710903202055

132. Ahmad, W., Zaidi, S.M.A., Mujeeb, M., Ansari, S.H., Ahmad, S. HPLC and HPTLC methods by design for quantitative characterization and in vitro anti-oxidant activity of polyherbal formulation containing Rheum emodi. J. Chromatogr. Sci. 52, 911-918 (2014)

133. Genovese, S., Tammaro, F., Menghini, L., Carlucci, G., Epifanoa, F., Locatellia, M.: Comparison of three different extraction methods and HPLC determination of the anthraquinones aloeemodine, emodine, rheine, chrysophanol and physcione in the Bark of Rhamnus alpinus L. (Rhamnaceae). Phytochem. Anal. 21, 261-267 (2010). https://doi.org/10.1002/pca.1195

134. Nagia, F.A., EI-Mohamedy, R.S.R.: Dyeing of wool with natural anthraquinone dyes from Fusarium oxysporum. Dyes Pigments 75, 550-555 (2007)

135. Farizadeh, K., Montazer, M., Yazdanshenas, M.E., Rashidi, A., Malek, A.: Extraction, identification and sorption studies of dyes from madder on wool. J. Appl. Polym. Sci. 113, 3799-3380 (2009)

136. Albertsson, P.A.: Aqueous biphasic systems: properties andapplications in bioseparation. In: Rogers, R.D., Eiteman, M.A. (eds.) Aqueous biphasic separations : biomolecules to metal ions, pp. 21-30. Plenum, New York (1995)

137. Chen, T., Liu, Y., Zou, D., Chen, D., You, J., Zhou, G., Sun, J., Li, Y.: Application of efficient stretgy based on liquid-liquid extraction, high speed counter-concurent chromatography and preparative HPLC for the rapid enrichment, separation and 
isolation of four anthraquinones from Rheum tanguticum. J. Sep. Sci. 37, 165-170 (2014)

138. Lesellier, E., West, C.: The many faces of packed column supercritical fluid chromatography-a critical review. J. Chromatogr. A 1382, 2-46 (2015). https://doi.org/10.1016/j.chroma.2014.12.083

139. Wolfender, J., Marti, G., Thomas, A., Bertranda, S.: Current approaches and challenges for the metabolite profiling of complex natural extracts. J. Chromatogr. A 1382, 136-164 (2015)

140. Selvaraj, R., Murty, V., Varadavenkatesan, T., Sekar, R., Ramesh, V.: Aqueous two phase systems for the recovery of biomolecules-a review. Sci. Technol. 1, 7-16 (2011). https://doi.org/ 10.5923/j.scit.20110101.02

141. El-Najjar, N., Gali-Muhtasib, H., Ketola, R.A.: The chemical and biological activities of quinones: overview and implications in analytical detection. Phytochem. Rev. 10, 352 (2011)

142. Tan, Z.J., Li, F.F., Xu, X.L.: Extraction and purification of anthraquinones derivatives from Aloe vera L. using alcohol/ salt aqueous two-phase system. Bioprocess Biosyst. Eng. 36(8), 1105-1113 (2013). https://doi.org/10.1007/s00449-012-0864-4

143. Toth, Z.A.: Isolation and determination of alizarin in cell cultures of Rubia tinctorum and emodin in dermocybe sanguineausing solid-phase extraction and high-performance liquid chromatography. J. Chromatogr. 630, 423-428 (1993)

144. Hu, H., Fujie, K.K.U.: Development of a novel solid phase extraction method for the analysis of bacterial quinones in activated sludge with a higher reliability. J. Biosci. Bioeng. 87(3), 378-382 (1999)

145. Bielicka-Daszkiewicz, K., Hadzicka, M., Voelkel, A.: Optimization of SPE/GC/HPLC analytical procedure for determination of phenol, quinones, and carboxylic acids in water samples. ISRN Chromatogr. (2012). https://doi.org/10.5402/2012/680929

146. Ding, L., Wang, Y., Yue, C., Wu, Z., Sun, Y., Wang, M., Li, R.: Separation of protein-binding anthraquinones from Semen Cassiae using two-stage foam fractionation. Process 7(463), 1-15 (2019)

147. El-Najjar, N., Gali-Muhtasib, H., Ketola, R.A., Vuorela, P., Urtti, A., Vuorela, H.: The chemical and biological activities of quinones: overview and implications in analytical detection. Phytochem. Rev. 10(3), 353 (2011). https://doi.org/10.1007/ s11101-011-9209-1

148. Khouri, H.E., Ibrahim, K.R.: Purification and some properties of five anthraquinone specific glucosyltransferases from Cinchona succirubra cell suspension culture. Phytochemistry 26(9), 25312535 (1987). https://doi.org/10.1016/S0031-9422(00)83870-4

149. Brock, B.J., Riebele, S., Gold, M.H.: Purification and haracterization of a 1,4-benzoquinone reductase from the basidiomycete Phanerochaete chrysosporium. Appl. Environ. Microbiol. 61(8), 3076-3081 (1995)

150. Attar-ur-Rahman, F.R.S.: Studies in natural products chemistry, vol. 58. Elsevier, Amsterdam (2018)

151. Amro, B.I.H., James, K.C., Turner, T.D.: A quantitative study of dyeing with lawsone. J. Soc. Cosmet. Chem. 45, 159-165 (1994)

152. Ashutosh, K.: Pharmacognosy and pharmacobiotechnology. Naw Age International New Delhi, New Delhi (2003)

153. Rondón, M., Moncayo, S., Cornejo, X., Santos, J., Villalta, D., Siguencia, R., Duche, J.: Preliminary phytochemical screening, total phenolic content and antibacterial activity of thirteen native species from Guayas province Ecuador. J. King Saud Univ. Sci. 30(4), 500-505 (2018)

154. Dongxiu, H., Bo, C., Qingqing, T., Shouzhou, Y.: Simultaneous determination of five anthraquinones in medicinal plants and pharmaceutical preparations by HPLC with fluorescence detection. J. Pharm. Biomed. Anal. 49(4), 1123-1127 (2009)

155. Sameh, A., Naoya, K., Kaname, O., Toshihide, M., Hiromasa, K., Kenichiro, N., Naotaka, K.: An ultrasensitive and highly selective determination method for quinones by high-performance liquid chromatography with photochemically initiated luminol chemiluminescence. J. Chromatogr. A 1216(18), 3977-3984 (2009)

156. Schneiderman, M.A., Sharma, A.K., Lock, D.C.: Determination of anthraquinone in paper and wood using supercritical fluid extraction and high-performance liquid chromatography with electrochemical detection. J. Chromatogr. A 409, 343-353 (1987)

157. Samman, D., Amin, F.M.: Titrimetric microdetermination of quinone and hydroquinone by amplification reactions. Mikrochim. Acta (1983). https://doi.org/10.1007/BF01204830

158. Hulanicki, A., Maj-Żurica, M., Glab, S.: Ttrimetry I potentiometry. In: Reedjk, J. (ed.) Reference module in chemistry, molecular sciences and chemical engineering, molecular sciences and chemical engineering, pp. 114-121. Elsevier, Amsterdam (2013)

159. Takahashi, H., Yoshimi, M.: Potentiometric redox titration of quinone in carbon black with $\mathrm{NaBH}_{4}$ and $\mathrm{I}_{2}$. Carbon 17(2), 109-114 (1979)

160. Castaignède, V., Durliat, H., Comtat, M.: Amperometric and potentiometric determination of catechin as model of polyphenols in wines. Anal. Lett. 36(9), 1707-1720 (2003). https://doi. org/10.1081/AL-120023610

161. Michelitsch, A., Rückert, U., Rittmannsberger, A., Seger, A., Strasser, H., Likussar, W.: Accurate determination of oosporein in fungal culture broth by differential pulse polarography. J. Agric. Food Chem. 52(6), 1423-1426 (2004)

162. Jiying, P., Yinghui, W., Kefu, Y.: Sensitive determination of quinones by high-performance liquid chromatography-electroscopy ionization-tandem with methanol derivatization. Jpn. Soc. Anal. Chem. 32, 335-340 (2018)

163. Boldizsár, I., Szúcsb, Z., Füzfai, Z., Molnár-Perl, I.: Identification and quantification of the constituents of madder root by gas chromatography and high-performance liquid chromatography. J. Chromatogr. 1133(1-2), 259-274 (2006)

164. Naoya, K., Naotaka, K.: Analytical techniques for the determination of biologically active quinones in biological and environmental samples. J. Pharm. Biomed. Anal. 87, 261-270 (2014)

165. Pääkkönen, T., Liitiä, T., Tamminen, T., Jääskeläinen, A.-S.: Determination of quinones in pulp by UV/Vis reflectance. In: Proceedings of the 11th European workshop on lignocellulosics and pulp, Hamburg, Germany, (2010)

166. Abdollahi, H., Bagheri, L.: Simultaneous spectrophotometric determination of $\mathrm{p}$-benzoquinone and chloranil after microcrystalline naphthalene extraction by using genetic algorithm-based wavelength selection-partial least squares regression. Anal. Sci. 20(12), 1701-1706 (2004). https://doi.org/10.2116/analsci.20. 1701

167. Iskander, M., Madlene, H.A.A., Khalil, L.: H: Spectrophotometric determination of some quinones. Anal. Lett. 28, 1513-1523 (1995)

168. Medien, H.A.A., Zahran, A.A.: Spectrophotometric kinetic and determination of quinones and barbiturates. Spectrochim. Acta A 57, 2505-2511 (2001)

169. Medien, H.A.A.: New method for spectrophotometric determination of quinones and barbituric acid through theirs reaction. A kinetic study. Spectrochim. Acta A 52, 1679-1684 (1996)

170. Elujoba, A.A., Ajulo, O.O., Iweibo, G.O.: Chemical and biological analyses of Nigerian Cassia species for laxative activity. J. Pharm. Biomed. Anal. 7(12), 1453-1457 (1989)

171. Hong, Z., Fang, G., Hua, Z., Li, K.: Determination of anthraquinone content in lac dye through combined spectrophotometry and HPCE. Proced. Eng. 18, 86-94 (2011)

172. Dexian, W., Gengliang, Y., Xiurong, S.: Determination of pKa values of anthraquinone compounds by capillary electrophoresis. Electrophoresis 22, 464-469 (2001) 
173. Gevrenova, R.: Determination of natural colourants in plant extracts by highperformance liquid chromatography. J. Serb. Chem. Soc. (2010). https://doi.org/10.2298/JSC091027071G

174. Canamares, M.V., Garcia-Ramos, J.V., Domingo, C., SanchezCortes, S.: Surface-enhanced Raman scattering study of the adsorption of the anthraquinone pigmentalizarin on Ag nanoparticles. J. Raman Spectrosc. 35, 921-927 (2004)

175. Makuraza, J., Pogrebnaya, T., Pogrebnoi, A.: Vibrational and electronic spectra of natural dyes constituents for solar cell application: DFT and TDDFT Study. Int. J. Mater. Sci. Appl. 4, 314-324 (2015). https://doi.org/10.11648/j.ijmsa.20150405.16

176. Marcaida, I., Maguregui, M., Morillas, H., García-Florentino, C., Pintus, V., Aguayo, T., Campos-Vallette, M., Madariaga, J.: Optimization of sample treatment for the identification of anthraquinone dyes by surface-enhanced Raman spectroscopy. Anal. Bioanal. Chem. 409, 2228 (2017). https://doi.org/10.1007/ s00216-016-0169-6

177. Chen, K., Leona, M., Vo-Dinh, K.-C., Yan, F., Wabuyele, M.B., Vo-Dinh, T.: Application of surface-enhanced Raman scattering (SERS) for the identification of anthraquinone dyes used in works of art. J. Raman Spectrosc. 37(4), 520-527 (2006). https:// doi.org/10.1002/jrs.1426

178. Stagge, S., Cavka, A., Jönsson, L.J.: Identification of benzoquinones in pretreated lignocellulosic feedstocks and inhibitory effects on yeast. AMB Express (2015). https://doi.org/10.1186/ s13568-015-0149-9

179. Roy, S., Jayanta, M.: Identification of quinones and coumarins in Swietenia macrophylla leaf. In: Proceedings: Recent trends and experimental approaches in science, technology,and nature, Jodhpur, India, pp 302-305 (2016)

180. Degani, L., Riedo, C., Gulmini, G., Chiantore, O.: From plant extracts to historical textiles: characterization of dyestuff by GC-MS. Chromatographia 77, 1683-1696 (2014)

181. Tripathi, B., Bhatia, R., Pandey, A., Gaur, J., Chawala, G., Walia, S., Choi, E.H., Attri, P.: Potential antioxidant anthraquinones isolated from Rheum emodi showing nematicidal activity against Meloidogyne incognita. J. Chem. 2014, 652526 (2014). https:// doi.org/10.1155/2014/652526

182. Bhuyan, R., Saikia, C.N.: Isolation of colour components from native dye-bearing plants in nothern India. Bioresour. Technol. 96, 365-372 (2005)

183. Vankar, P., Shanker, R., Mahanta, D., Tiwari, S.C.: Ecofriendly sonicator dyeing of cotton with Rubia cardifolia Linn. using biomordant. Dyes Pigments 76, 207-2012 (2008)

184. Mishchenko, N.P., Vasileva, E.A., Gerasimenko, A.V., Grigorchuk, V.P., Dmitrenok, P.S., Fedoreyev, S.A.: Isolation and structure determination of echinochrome A oxidative degradation products. Molecules 25(20), 4778 (2020)

185. Lal, C., Asm, R., Pareek, P., Shakyawar, D., Sharma, K., Sharma, M.: Juglans nigra: chemical constitution and its application on Pashmina (Cashmere) fabric as a dye. J. Nat. Prod. Plant Resour. 1, 13-19 (2011)

186. Dongmei, Y., Shuangyue, L., Shujun, L., Jian, L., Molong, S., Yan, J.: Effect of juglone from Juglans mandshurica bark on the activity of wood decay fungi. For. Prod. J. 59(9), 79 (2009)

187. Vukic, M.D., Vukovic, N.L., Djelic, G.T., Popovic, S.L., Zaric, M.M., Baskic, D.D., Krstic, G.B., Tesevic, V.V., Kacaniova, M.M.: Antibacterial and cytotoxic activities of naphthoquinone pigments from Onosma visianii Clem. EXCLI J. 16, 73-88 (2017). https://doi.org/10.17179/excli2016-762

188. Yue, S., Tang, Y., Li, S., Duan, J.-A.: Chemical and biological properties of quinochalcone C-glycosides from the florets of Carthamus tinctorius. Molecules 18(12), 15220-15254 (2013). https://doi.org/10.3390/molecules 181215220

189. Kazuma, K., Takahashi, T., Sato, K., Takeuchi, H., Matsumoto, T., Okuno, T.: Quinochalcones and flavonoids from fresh florets in different cultivars of Carthamus tinctorius L. Biosci. Biotechnol. Biochem. 64(8), 1588-1599 (2000). https://doi. org/10.1271/bbb.64.1588

190. Bhuiyan, R.M.A., Islam, A., Ali, A., Islam, M.N.: Colour and chemical constituents of natural dye henna (Lawsomia Intermis L.) and its application in the colouration of textiles. J. Clean. Prod. 167, 14-22 (2017)

191. Maciej, Z., Błażej, G., Hubert, B., Schroeder, G.: The cortinarius fungi dyes as sensitizers in dye-sensitized solar cells. Int. J. Photoenergy (2015). https://doi.org/10.1155/2015/653740

192. Son, E.J., Kim, J.H., Kim, K., Park, C.B.: Quinone and its derivatives for energy harvesting and storage materials. J. Mater. Chem. A 4(29), 11179-11202 (2016). https://doi.org/ 10.1039/C6TA03123D

193. Khattak, S., Rafique, S., Hussain, T., Inayat, F., Bashir, A.: Colour fastness and tensile strength of ccotton fabric dyed with natural extracts of Alkanna tinctoria by continuous dyeing technique. J. Chem. Soc. Pak. 37, 903-909 (2015)

194. Nilani, P., Saravanan, K.: Formulation and evaluation of herbal hair dye: an ecofriendly process. J. Pharmacol. Sci. Res. 2(10), 648-656 (2010)

195. Md. Tushar, U., Md. Abdur, R., Ariful, H., Murshid, J.Q., Chowdhury, A.-M., Md Moshrur, R., Farid, A.: Extraction of dye from natural source (LAC) \& its application on leather. Am. Sci. Res. J. Eng. Technol. Sci. 34(1), 1-7 (2017)

196. Önal, A.: Extraction of dyestuff from madder plant (Rubia tinctorum L.) and dyeing of wool feathered-leather and cotton. Turk. J. Chem. 20, 204-213 (1996)

197. Bukhari, M.N., Shabbir, M., Rather, L.J., Shahid, M., Singh, U., Khan, M.A., Mohammad, F.: Dyeing studies and fastness properties of brown naphtoquinone colorant extracted from Juglans regia $\mathrm{L}$. on natural protein fibre using different meta salt mordants. Text. Cloth. Sustain. (2017). https://doi.org/10. 1186/s40689-016-0025-2

198. Mohd, Y., Faqeer, M., Mohd, S., Khan, M.A.: Eco-dyeing of wool with Rubia cordifolia root extract: Assessment of the effect of Acacia catechu as biomordant on color and fastness properties. Text. Cloth. Sustain. (2016). https://doi.org/10. 1186/s40689-016-0021-6

199. Vankar, P.S., Shanker, R., Mahanta, D., Tiwari, S.C.: Ecofriendly sonicator dyeing of cotton with Rubia cordifolia Linn. using biomordant. Dyes Pigments 76(1), 207-212 (2008). https://doi.org/10.1016/j.dyepig.2006.08.023

200. Malomo, D., Abimbade, S.A., Oluwaseun, A.K., Ghareba, O.E.: Likely mechanism of dye adhesion on fabrics. Int. J. Adv. Sci. Eng. Technol. 5(3), 1-7 (2017)

201. Kamel, M.M., El Zawahry, M.M., Ahmedm, N.S.E., Abdelghaffar, F.: Ultrasonic dyeing of cationized cotton fabric with natural dye. Part 2: Cationization of cotton using Quat 188. Ind. Crops Prod. 34, 1410-1417 (2011)

202. Khalil-Abad, M.S., Yazdanshenas, M.E., Nateghi, M.R.: Effect of cationization on adsorption of silver nanoparticles on cotton surfaces and its antibacterial activity. Cellulose 16, 1147-1157 (2009)

203. Hong, K.H., Bae, J.H., Jin, S.R., Yang, J.S.: Preparation and properties of multi-functionalized cotton fabrics treated by extracts of gromwell and gallnut. Cellulose 19(2), 507-515 (2012)

204. Iqbal, J., Bhatti, I.A., Adeel, S.: Effect of UV radiation on dyeing of cotton fabric with extracts of henna leaves. Indian J. Fibre Text. Res. 33(2), 157-162 (2008)

205. Balamurali, B., Victor, B., Dennis, W.: Hess: fabrication of "roll-off" and "sticky" superhydrophobic cellulose surfaces via plasma processing. Am. Chem. Soc. 24(9), 4785-4790 (2008) 
206. Hanker, P.S.V., Rakhi, S.: Ecofriendly ultrasonic natural dyeing of cotton fabric with enzyme pretreatments. Desalination 230(1-3), 62-69 (2008)

207. Hoefnagels, H.F., Wu, D.G., Ming, W.: Biomimetic superhydrophobic and highly oleophobic cotton textiles. Langmuir 23(26), 13158-13163 (2007)

208. Broadbent, A.D.: Basic principles of textile colouration. Society of Dyers and Colourists, Sherbrooke (2001)

209. Clark, M.: Handbook of textile and industrial dyeing, vol. 1. Woodhead Publishing Limited, Cambridge (2011)

210. Shabbir, M., Rather, L.J., Bukhari, M.N., Khan, M.A., Mohammad, F.: First-time application of biomordants inconjunction with the Alkanna tinctoria root extractfor eco-friendly wool dyeing. J. Nat. Fibers (2018). https://doi.org/10.1080/15440 478.2018.1441085

211. Ferda, E., Semra, S., Cengiz, T., Fikret, Y., Adem, O.: Effect of acid pretreatment on the dyeing performance of walnut (Juglans regia) leaves on wool fibers. Fibers Polym. 16(8), 1657-1662 (2015)

212. Shahin, M.F., Ahmed, R.M., Marie, M.M.: Optimizing the dyeing process of alkali-treated polyester fabric with dolu natural dye. Int. J. Eng. Res. Appl. 4(6), 35-40 (2014)

213. Cigdem, S., Nahide, G., Deniz, A.C.: Synthesis of N-, S-, $\mathrm{O}$-substituted quinone dyes and their dyeability on polyester fibers. Progress Organ. Coat. 98, 39-42 (2016)

214. Lee, J.J., Shim, W.S., Kim, I.S., Kim, J.P.: Dyeing and fastness properties of vat dyes on a novel regenerated cellulosic fiber. Fibers Polym. 6, 244-249 (2005)

215. Arora, A., Gupta, D., Rastogi, D., Gulrajani, M.: Naphthoquinone colorants from Arnebia nobilis Rech.f. Color. Technol. 128(5), 350-355 (2012). https://doi.org/10.1111/j.1478-4408. 2012.00383.x

216. Mousa, S.-K., Siyamak, S., Somaye, M.: Thermodynamic and kinetic studies of the adsorption behaviour of the natural dye cochineal on polyamide 66 . Colour Technol. 134, 308-314 (2018)

217. Gupta, D., Kumari, S., Gulrajani, M.: Dyeing studies with hydroxyanthraquinones extracted from Indian madder. Part 1: dyeing of nylon with purpurin. Color. Technol. 117, 328-332 (2006). https://doi.org/10.1111/j.1478-4408.2001.tb00084.x

218. Gallo, F.R., Multari, G., Giambenedetti, M., Federici, E.: Chemical fingerprinting of Lawsonia inermis L. using HPLC. HPTLC Densitom. Phytochem. Anal. 19(6), 550-559 (2008). https://doi.org/10.1002/pca.1084

219. Lekouch, N., Sedki, A., Nejmeddine, A., Gamon, S.: Lead and traditional Moroccan pharmacopoeia. Sci. Total Environ. 280(1-3), 39-43 (2001). https://doi.org/10.1016/s00489697(01)00801-4

220. Tavoos, B., Najafpour, G.D., Morteza, H.: Evaluation of antimicrobial and dyeing properties of walnut (Juglans regia L.) green husk extract for cosmetics. Soc. Dyers Colour. 134, 71-81 (2017)

221. Chattopadhyay, P., Chatterjee, S., Sen, S.: Biotechnological potential of natural food grade biocolorants. Afr. J. Biotechnol. 7, 133 (2008)

222. Jinchu, I., Jyothi, R., Pandurangan, N., Ks, S., Achuthan, K.: Anthraquinones: a probe to enhance the photovoltaic properties of DSSCs. Int. J. Electr. Comput. Eng. 6(3), 1274-1280 (2016)

223. Cheng, M., Xichuan, Y., Cheng, C., Jianghua, Z., Fugu, Z., Licheng, S.: Dye-sensitized solar cells based on hydroquinone/benzoquinone as bio-inspired redox couple with different counter electrodes. Phys. Chem. Chem. Pys. 15, 15146-15152 (2013)

224. Neeranuch, C., Kanlaya, J., Patiwat, S., Waya, S., Weerachai, P., Duang, B.: Electrocoagulation of quinone pigments. Molecules 11, 514-522 (2006)

225. Howben, W.: Science of synthesis. In: Griesbeck, A.G. (ed.) Compounds with molecular carbon-heteroatom bonds, vol. 28. Georg Thieme Verlang K. G., Stuttgart (2006)

Publisher's Note Springer Nature remains neutral with regard to jurisdictional claims in published maps and institutional affiliations.

\section{Authors and Affiliations}

\section{Benson Dulo ${ }^{1,3} \cdot$ Kim Phan $^{1} \cdot$ John Githaiga ${ }^{2} \cdot$ Katleen Raes $^{3} \cdot$ Steven De Meester ${ }^{1}$}

1 Laboratory for Circular Process Engineering (LCPE), Department of Green Chemistry and Technology, Ghent University Campus Kortrijk, Graaf Karel de Goedelaan 5, 8500 Kortrijk, Belgium

2 Department of Manufacturing, Industrial and Textile Engineering, Moi University, Box 3900-30100, Eldoret, Kenya
3 Research Unit VEG-I-TEC, Department of Food Technology, Safety and Health, Ghent University Campus Kortrijk, Graaf Karel de Goedelaan 5, 8500 Kortrijk, Belgium 